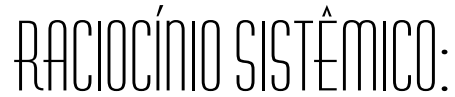

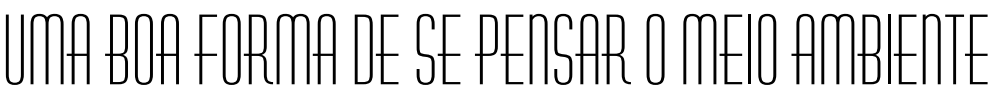 \\ MANUEL FOLLEDO*
}

\section{PRIMEIRA PARTE}

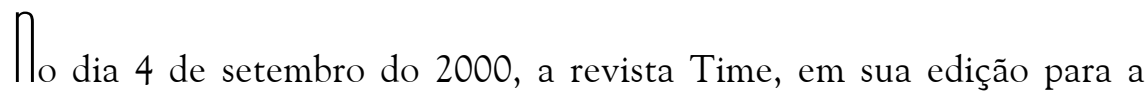
América Latina, publicou um artigo sobre o descongelamento do ,rtico devido ao aquecimento ambiental. Este efeito, afirma o artigo, é causado pelos gases emitidos pela combustão de combustíveis fósseis. O título do artigo "The Big Meltdown," que antecipa o conteúdo, é acompanhado por um grito de alerta na forma de subtítulo: "As the temperature rises in the Artic, it sends us a chilli around the planet." Alguns dados apresentados são estarrecedores, mas fáceis de transcrever: até 4 graus centígrados de aumento de temperatura no Alasca, Sibéria e parte do Canadá e perda de $40 \%$ da espessura da capa de gelo que cobre uma área 6\% menor que em 1980.

Devo confessar que a leitura dessa matéria gerou um forte efeito em mim: fiquei pensando no mundo que espera por meus filhos e eventuais netos (falo filhos e netos e não tataranetos ou descendentes de um futuro distante). Se não bastasse o exemplo do descongelamento do Ártico, duas outras notícias foram divulgadas pela mídia nesses dias. Uma delas nos informava que cientistas da NASA observaram que a camada de ozônio aumentou muito além do previsto pela agência. $O$ buraco cobre hoje uma área de 75 milhões de quilômetros quadrados. A segunda notícia: um novo vazamento, produzido pela Petrobrás, contamina os rios com 75 mil litros de óleo.

Parecia que a mídia estava disposta a derrubar meu otimismo, talvez ingênuo, que derivava da minha confiança de que a utilização integral do Raciocínio Sistêmico (disciplina e prática que aqui apresento) na análise e gestão dos problemas ambientais, tanto em seus aspectos metodológicos como políticos e sociais, viesse a dar solução ou a minimizar de maneira significativa muitos dos problemas que hoje nos conturbam. Mas apesar do flamante pessimismo, continuo achando que uma solução qualquer será finalmente implementada por caminhos que, implicitamente ou explicitamente, utilizem essa metodologia, já que, se existe alguma chance na recuperação de nosso planeta, ela terá como pressuposto básico uma mudança global da perspectiva com que as pessoas se relacionam com o ecossistema. É atrás dessa mudança que todos os leitores destas linhas também estão. É isso o que nos faz recuperar o otimismo.

As sociedades, as cidades, as comunidades, as instituições, as diretrizes políticas e seus modelos econômicos formam subsistemas, todos eles componentes de 
um ecossistema maior, que também inclui as populações biológicas e os geo-sistemas. Daí o porquê de os ecossistemas serem estruturas altamente complexas com poderosas correlações dinâmicas entre si e entre seus componentes. Fica evidente que, para que a hercúlea missão de definir ações e de elaborar políticas e diretrizes para o meio ambiente seja eficiente, não podemos prescindir da compreensão da hipercomplexidade destas estruturas e da utilização de metodologias adequadas para lidar com ela. Entretanto, a metodologia per se seria somente um requinte acadêmico se ela não fosse orientada a produzir uma mudança radical de comportamento, de valores éticos e de princípios, tanto ao nível individual como coletivo. Isso pressupõe compromissos de todos os envolvidos.

Encontrar caminhos para realizar essa missão não pode ser entendido como uma tarefa própria de indivíduos ou de grupos de especialistas em algumas das disciplinas vinculadas ao meio ambiente. A sociedade como um todo deve participar, cada um com o seu papel. Mas, para que isso aconteça, deve-se definir de antemão uma intencionalidade estratégica de disseminação dos conhecimentos necessários para que a sociedade como um todo possa participar. Junto com essa intencionalidade devemos aplicar (e/ou desenvolver) metodologias de universalização e compartilhamento dos princípios, postulados e processos de aprendizado que uma humanidade ecologicamente responsável precisa. É necessário, também, o estabelecimento de uma base conceitual sólida, tanto para a gestão da mudança como também para seu monitoramento. Por outro lado, a diversidade de enfoques e de formas de participação que um movimento dessa natureza gerará faz com que outras duas necessidades apareçam em primeiro plano. A primeira delas é a elaboração de uma epistemologia para a disciplina que garanta a legitimidade das metodologias escolhidas em cada caso, e que derrube os questionamentos que venham a surgir baseados nos mais diversos interesses. " por essa razão que o avanço espistemológico não é um requinte acadêmico, e sim uma arma poderosa na luta pela defesa do meio ambiente. Nos próximos parágrafos darei início à apresentação de um caminho epistemológico. Mas, a esta altura, o propósito de minha contribuição será unicamente o de manifestar minha preocupação e provocar discussões entre os especialistas, deixando para um futuro trabalho seu desenvolvimento mais completo, não sem antes anunciar que esta epistemologia pode encontrar um apoio sólido nos conceitos do Raciocínio Sistêmico aqui resumidos.

A Segunda necessidade crítica é da adoção de uma linguagem universal que facilite a comunicação e permita a unificação conceitual da problemática ambiental. Aqui também a situação é grave, porque o problema ambiental constitui o centro da atenção de um amplo espectro de interessados e interesses: acadêmicos das mais diversas áreas, políticos, empresários ${ }^{1}$, $\mathrm{ONG}$ e público em geral. Não é estranho que o som de tão diversos discursos se assemelhe a uma moderna torre de Babel. Norgaard ${ }^{2}$ descreve esse fenômeno de forma muito aguda: “...um grande número de vozes diferentes contribui para a cacofonia. Muitas disciplinas científicas estão envolvidas, todas falando em suas linguagens especiais; os interesses econômicos estão assolando as dificuldades de normatização, e uma multidão de pessoas com 
conhecimento experiente crítico estão tentando ser ouvidas. O autor continua: “...reunir essas vozes é certamente inútil. Porém, a esperança mostra-se eterna e muitos de nós trabalhamos furtivamente buscando uma nova convergência de entendimento ... enfatizo a importância do entendimento para atingir a sustentabilidade." Estas considerações nos levam a identificar uma necessidade urgente da área: a utilização de uma linguagem comum que elimine a força desta cacofonia. Gostaria, através deste trabalho, de mostrar que podemos concordar com o fundamento do prenúncio de Norgaard que diz: "...desde que se desenvolva uma linguagem comum e se substitua o trabalho furtivo por uma militância explícita e cheia de sentido, podemos estar certos de que sim, é possível reunir essas vozes diferentes. Não só que é possível e útil; é também necessário."

Podemos, entretanto, identificar as causas de tanto barulho. No meu entender, uma das principais é a de que o meio ambiente constitui um sistema com altíssimo grau de complexidade, tanto de complexidade combinatorial, derivada do número de componentes sistêmicas e de suas interações, como de complexidade dinâmica, derivada do padrão de comportamento que as componentes sistêmicas têm ao longo do tempo. Minha expectativa é que, através de uma breve introdução dos instrumentos do Raciocínio Sistêmico (loops de feedback, estruturas sistêmicas, modelos, etc.), que apresentarei a seguir, o leitor possa vislumbrar o enorme potencial que essas ferramentas (simples) podem vir a desempenhar como linguagem de comunicação universal ${ }^{3}$, aliviando dessa maneira a angústia de Norgaard. Ferreira já antecipa um enfoque sistêmico quando analisa "soluções tentadas para o problema ambiental pelo Estado, mercado e comunidades" e qualifica estas interrelações como sendo "um oceano de irracionalidades acumuladas....entretanto há novas formas de pensar o conhecimento e a ação que possam abrir caminhos para alternativas políticas e subjetivas no contexto contemporâneo." É dentro desse espírito de otimismo crítico que colocamos a proposta da metodologia do RACIOCÍNIO SISTÊMICO como instrumento de aquisição de conhecimento e de sua validação. Muitos esforços já foram iniciados, muitos terão ainda que ser iniciados. Entretanto, é bom lembrar que: "For every complex problem there is always a simple solution. And it is wrong." (L. Mencken)

Em certa ocasião, J. Forrester, uns dos criadores da Dinâmica de Sistemas , componente fundamental do Raciocínio Sistêmico, perguntou a seus alunos sobre o efeito que teve para eles apreender os conceitos desta disciplina. Um deles deu a seguinte resposta: “eu aprendi a ler o jornal." Eu acho que a disseminação dos conceitos do Raciocínio Sistêmico, mesmo que seja num nível elementar, permitirá que um grande número de pessoas aprenda a ler o jornal. Penso também que esse fenômeno saber ler o jornal- produzirá uma revolução tão profunda que dificilmente o próprio Forrester concordaria com suas conseqüências.

\section{O ROTEIRO}

Na próxima seção, introduzirei o conceito de sistema, matéria-prima 
fundamental para a presente elaboração. Após isto, apresentarei noções sobre "loops de feedback," "sistemas de feedback" e "arquétipos sistêmicos." A essa altura, tentarei tornar a leitura um pouco mais atrativa com a inclusão de alguns exemplos simples que facilitem o entendimento e aumentem a motivação. Com isso, a base conceitual mínima estará completa. Depois, incluirei algumas questões sobre os caminhos metodológicos da ciência, tentando convencer o leitor de que o Raciocínio Sistêmico é uma alternativa válida para o estudo e gestão de situações onde não se verificam as condições para que seja aplicável o roteiro metodológico válido para as ciências naturais .

Estando o leitor convencido da impossibilidade de aplicar o caminho metodológico clássico, apresentarei a alternativa do Raciocínio Sistêmico, mais como uma heurística do que como uma solução algorítmica. Ele será introduzido como uma perspectiva de entendimento da realidade que, além de outros conteúdos, inclui um conjunto de habilidades e roteiros para a análise dos ecossistemas. Estas habilidade são as que nos permitirão utilizar o Raciocínio Sistêmico para aquisição, validação e disseminação de conhecimentos e, talvez o mais importante, para definir e avaliar políticas e planos de ação na área de gestão ambiental.

\section{O PRINCÍPÍO UNIFICADOR: O CONCEITO DE SISTEMA}

Em grande medida, o estresse da vida moderna emerge do fato de que as pessoas se sentem oprimidas por forças que elas não conseguem entender nem controlar. Podemos aqui identificar um estado que Carone, ao comentar o trabalho de Kafka, chama de "situação kafkiana." ${ }^{5}$ Os superpoderes kafkianos são hoje a globalização, o efeito estufa, o buraco na camada de ozônio, a destruição das florestas, os resíduos radioativos, e outros mil. Esse sentimento de impotência tem como raiz a falta de entendimento entre os sistemas dos quais as pessoas fazem parte. Eventos que aparecem como incompreensíveis quando vistos localmente tornam-se mais inteligíveis quando observados de uma perspectiva sistêmica mais ampla.

Paradoxalmente, apesar de vivermos em um universo repleto de sistemas complexos, poucas vezes fazemos esforço para tomarmos consciência da medida em quel esses sistemas controlam nossas vidas. Essa atitude induz, em muitas ocasiões, a um comportamento contra-producente; a ignorância ou o descaso com os conceitos sistêmicos -por parte de políticos, empresários e tomadores de decisões- fazem com que a escolha de uma nova política, elaborada com o objetivo de resolver um problema, ocasione reações em outras partes do sistema que contra-atacam a nova política. Nesse sentido, a observação de Forrester merece ser levada em conta: "Eu acredito que uma porcentagem muito alta das políticas e ações que se aplicam em um sistema tem pouco poder de alavancagem para produzir uma mudança na direção desejada. Entretanto, a maioria dos debates mais quentes nas comunidades, nas instituições e na área governamental ocorrem sobre políticas e diretrizes que não têm influencia alguma. Tais debates são uma perda de tempo e de energia que desvia a atenção das políticas que poderiam ser efetivas." ${ }^{6}$ 
Sem dúvida, todos os leitores desta revista têm idéias claras do que são os sistemas. Porém, para efeitos de unificação de seus significados, farei uma breve revisão desse conceito.

Um sistema consiste de:

- Elementos definíveis;

- Entre estes elementos existem relações -geralmente interrelações funcionais, de influência e/ou de circulação de informação- na forma de loops fechados. Um sistema é mais do que uma simples acumulação de elementos; o que determina seu comportamento é a estrutura das relações entre estes elementos;

- Um sistema é uma totalidade A primeira coisa que nos vêem à cabeça quando mencionamos a palavra sistema é a de uma totalidade. Entretanto, o mundo que nos rodeia, que chamamos de mundo real (ou universo), é excessivamente amplo e complexo para poder ser administrado ou estudado se nele incluímos todas suas componentes e todas as interações entre essas componentes. Surge então a necessidade de delimitar essa totalidade em função de nossos objetivos. Esses objetivos são os que definem a perspectiva com a qual olhamos as coisas. É justamente essa perspectiva que define, de maneira consciente ou inconsciente de nossa parte, os "limites" do que queremos observar ou gerenciar.

Assim, quando afirmamos que "um sistema é uma totalidade" estamos afirmando que é parte de um todo maior limitado por nossa perspectiva, que por sua vez está determinada pelo objetivo (explícito ou implícito, consciente ou inconsciente) de nossa observação. Consequentemente, cada vez que nos referirmos a um "sistema," estaremos incluindo automaticamente nossa perspectiva, que coloca limites ao sistema" de considerável importância definir claramente esses limites toda vez que nosso interesse seja entender ou gerenciar um determinado sistema e, mais ainda, se pretendemos representá-lo ou construir um modelo (seja este qualitativo ou quantitativo), principalmente se nossa intenção é realizar alguma forma de simulação do sistema real através do modelo. Isto é:

- Os sistemas são permeáveis às fronteiras que os unem com o ambiente que os rodeia e com os subsistemas maiores nos quais eles estão inseridos. As fronteiras podem ser materiais, como a pele do corpo humano, ou imaterial, como a inclusão a um grupo social. As fronteiras de um sistema são importantes por várias razões:

- As fronteiras asseguram (ou às vezes determinam) a identidade do sistema;

- As relações de troca entre um sistema e seu ambiente ocorrem principalmente em suas fronteiras; é aí que se determina o que entra e/ou o que sai dos sistemas (seus "inputs" e "outputs");

- Os sistemas têm usualmente um comportamento dinâmico ao longo do tempo. Este comportamento está geralmente associado ao propósito do sistema. Os sistemas biológicos (seres vivos) são determinados para assegurar sua auto-preservação 
(essencialmente via homeostasis);

- Dependendo da perspectiva, os elementos individuais de um sistema podem também ser considerados como sendo um sistema (ou um subsistema), e todo sistema pode também ser visto como sendo um subsistema de um sistema maior. A partir desta idéia toda uma hierarquia de sistemas poderá ser construída;

- Três dimensões fundamentais dos sistemas são: identidade, organização e orientação a objetivo (ou propósito - goal orientation). Por identidade entenderemos "estabilidade dentro da mudança (ou com mudança)"; por organização entenderemos o desenho e manipulação da complexidade; por orientação ao objetivo entenderemos "o destino do sistema."

\section{Algumas características importantes dos sistemas}

Os sistemas apresentam algumas características específicas. É o entendimento dessas características o que nos permitirá entender e gerenciar os ecossistemas. Entre as mais importantes mencionarei:

1.- As partes de um sistema (suas componentes ou subsistemas) devem estar todas presentes para que o sistema atinja de maneira ótima seu objetivo

Esta característica nem sempre é levada em conta pelos interventores ou atores do meio ambiente. Quanto o ecossistema perde -em termos de seu comportamento ótimo- quando uma floresta ou uma espécie é eliminada de alguma região? Até que ponto o efeito da eliminação de uma componente desse tipo é pequeno ou catastrófico a longo prazo? Como podemos saber de antemão todas as conseqüências da eliminação de partes de um ecossistema (de predadores, de presas, de fontes de água, etc.)?

2.- Num sistema, as partes devem estar interligadas de uma forma específica para que o sistema realize seu propósito. Cada subsistema tem seu propósito específico

As partes de um sistema não podem ser colocadas de maneira aleatória ou arbitrária sem mudar a natureza essencial do sistema. Não é qualquer árvore que pode substituir uma árvore de uma determinada espécie que foi cortada com fins comerciais, nem é a grama que vai desempenhar o papel que as árvores desempenhavam.

3.- Os sistemas mantêm estabilidade através de flutuações e ajustes: i.e., quando não são submetidos a grandes interferências externas, os sistemas possuem uma capacidade significativa de manter estabilidade através de interações, feedbacks e ajustes, que circulam de forma contínua entre os diversos componentes do sistema. A interferência externa destrói, com freqüência, as interações e mecanismos de feedback que poderiam trazer o sistema de volta à estabilidade. Entretanto, um modelo mental perverso domina a lógica e as ações dos predadores do sistema ambiental: a de que o meio ambiente tem -por mecanismos e razões mágicas- a capacidade incondicional de retornar à estabilidade que eles destruíram em sua procura irracional 
pelo lucro de curto prazo.

Um trágico exemplo de interferência irracional externa, causada intencionalmente ou não pelo aumento do transporte e comércio entre diferentes regiões do planeta, é o fenômeno da invasão de espécies. Richard Mack e outros autores $1^{7}$ analisam este fenômeno em um brilhante artigo que, além de numerosos exemplos, faz uso de maneira implícita de uma variedade de conceitos sistêmicos. Alguns dos exemplos citados pelos autores incluem importantes ecossistemas brasileiros.

4.- As relações de causalidade circular acontecem através da transmissão e do retorno de informação entre suas partes componentes e subsistemas

O padrão de comportamento de duas ou mais variáveis dentro de um sistema está afetada pelos vínculos de interdependência. As interelações revelam como os "loops de feedback" se organizam para gerar estruturas responsáveis por produzir o comportamento observado no sistema.

Um mérito específico do Raciocínio Sistêmico é captar o poder que oferece o conceito de loop de feedback e de estrutura como princípios unificadores e utilizar esses conceitos como instrumentos para o entendimento e gestão dos sistemas.

Em alguns sistemas (ou em relação a algumas variáveis de certos sistemas) o feedback e/ou processo de ajuste é quase imediato, sendo nesse caso mais fácil sua identificação. Em outras ocasiões, o efeito de uma alteração em uma parte do sistema pode retornar ao local onde aconteceu a alteração após um certo tempo, ou através de uma intrincada trajetória. Todavia, o efeito pode viajar por componentes externas ao sistema antes de voltar a atingir a componente que deu origem ao loop. Nestes casos, a identificação dos loops de feedback torna-se um processo mais complexo, principalmente quando não se dispõe de metodologia adequada, ou se na disciplina com a qual se estuda o sistema esse conceito não está sendo utilizado.

Além disto, em sistemas formados por numerosos loops de feedback e de demoras significativas, as causas de um determinado sintoma observado podem se localizar em uma parte totalmente diferente do ponto de sua manifestação no instante da observação. Isso conduz os administradores desse sistema a aplicar ações que mais tarde se mostrarão totalmente irrelevantes.

O conceito de loop de feedback nos permite entender melhor alguns fenômenos sistêmicos familiares, mas não identificados como tais, como por exemplo, o fenômeno das conseqüências intencionais e não intencionais das ações executadas sobre um sistema. Quando alguém executa uma ação num sistema, o faz com uma determinada intenção: conduzir o sistema a um comportamento desejado pelo executor da ação. Mas o efeito desta ação pode transmitir-se pelas diferentes componentes do sistema e transformarse em efeitos não intencionais. ${ }^{8}$ complexidade

5.- Os sistemas (principalmente os ecossistemas) apresentam alto grau de

Ao serem perguntados sobre o tema da complexidade nos sistemas vivos, a maioria das pessoas indica o grande número de espécies que habita nosso planeta. Entretanto, não são tanto os números que fazem o mundo vivo altamente complexo, mas 
a enorme variedade de formas nas quais as espécies se combinam e interagem. Como exemplo, suponhamos que 100 espécies habitam uma região. Haverá então 4950 pares possíveis através dos quais as espécies se interagirão duas a duas. Entretanto, se calcularmos todas as combinações possíveis entre as espécies, obteremos um número quase impossível de ser representado.

Uns dos aspectos menos entendidos dos ecossistemas é a forma em que as interações locais afeta o comportamento global e a dinâmica de toda a comunidade. Questões tais como heterogeneidade espacial e redes de interações entre espécies desempenham um papel importante na viabilidade das estratégias de gestão dos ecossistemas, especialmente em altered landscapes. Outra vez o trabalho de Mack (2000) serve de exemplo para estes conceitos.

\section{Enfoques sobre sistemas em diferentes campos da ciência}

- O enfoque da matemática e da física (Newton): trata geralmente sistemas de equações, especialmente equações diferenciais. A dinâmica clássica consiste essencialmente na teoria das equações diferenciais.

- O enfoque da Teoria Geral de Sistemas ou Ciência dos Sistemas (van Bertalanffy, ${ }^{9}$ Rapoport $\left.{ }^{10}\right)$ : considera os sistemas como sendo entidades matemáticas e utiliza o método matemático para analisá-los e classificá-los.

- O enfoque da Dinâmica de Sistemas (Forrester at al. MIT, 1960): J. Forrester $^{11}$ desenvolveu um método poderoso -a Dinâmica de Sistemas- para descrever as interrelações dos componentes de um sistema com base principalmente em duas ferramentas: (a) utilizando diagramas de "loops causais" e diagramas de "stock-and-flow" e (b) a aplicação da simulação para a análise do comportamento dos sistemas. Forrester se apóia rigidamente nos princípios da Dinâmica de Sistemas -disciplina que ele fez avançar de maneira considerável- e coloca os modelos de simulação por computador como condição "sine qua non" para a validade dos resultados. A diferença deste enfoque em relação ao enfoque das equações diferenciais é que, na Dinâmica de Sistemas, as soluções fechadas não desempenham um papel significativo nem constituem seu objetivo.

- O enfoque da "Quinta Disciplina (Peter Senge" segue um roteiro mais "soft" que a proposta de Forrester no que se refere à construção de modelos. Em compensação, ele inclui de maneira mais significativa o lado humano através dos modelos mentais e da inclusão de "arquétipos sistêmicos" que ampliam de forma considerável o conceito de "estruturas genéricas" proposto por Forrester. $\bigcirc$ enfoque que apresento neste trabalho inclui, em essência, a proposta da escola de Senge, com seu campo de aplicação ampliado aos ecossistemas.

- O enfoque "ecológico-biológico: trata principalmente de 
ecossistemas. Seu principal representante é Odum ${ }^{14}$. A visão sistêmica dos ecologistas é geralmente mais qualitativa que a visão derivada da Dinâmica de Sistemas.

O próximo parágrafo tem por objetivo apresentar as bases conceituais mínimas que permitam a leitura dos temas posteriormente colocados.

\section{UMA BREVE INTRODUÇÃO AOS “LOOPS DE FEEDBACK” 15}

Uma estrutura de feedback existe dentro de um sistema quando uma determinada ação ou mudança de valor de uma variável é, mais tarde, influenciada pelas conseqüências desta mesma ação ou mudança. $O$ retorno da influência pode ser rápido e diretamente aparente, ou pode ser indireto, não imediato, sujeito a demoras e a influências causadas por alterações em outras variáveis. O comportamento do sistema está determinado pela estrutura de loops de feedback entre seus componentes. Por isso, o estudo de um sistema, enquanto sistema, consiste não só no estudo de cada componente, mas principalmente, no estudo de suas interações, isto é, de seus loops de feedback. Por outra parte, esse conhecimento é essencial para a gestão do sistema, principalmente para o planejamento de qualquer tipo de intervenção sistêmica que tenha como propósito levar o sistema a um comportamento desejado, ou que vise evitar comportamentos indesejados

Stinchcombe (1968) se coloca como objetivo o estudo e rastreamento dos padrões de explicação no campo das ciências sociais. Não é por acaso que ele acaba descobrindo a riqueza dos "feedback loops" como conjuntos de padrões capazes de explicar e de por em evidência estruturas lógicas e conceituais que numerosos cientistas sociais desenvolveram ao longo do tempo e que comunicaram com diferentes terminologias ${ }^{16}$. Na colocação deste autor, os "feedback loops" aparecem em dois aspectos interessantes: por um lado, como estruturas básicas da construção conceitual e, por outro lado e não menos importante, como uma linguagem e códigos de comunicação dessas estruturas. As estruturas de "feedback loops" são chamadas por Stinchcome de "functional casual imaginery," que as define como situações onde: "As conseqüências de um comportamento ou arranjo social são elementos essenciais das causas desses comportamentos."

Podemos considerar que existem quatro níveis hierárquicos de estruturas de feedback: o nível de variável, o de vínculo (ou conexão), o de loops de fedback e o de sistemas de feedback. Uma variável é uma quantidade que muda ao longo do tempo. Ela pode ser uma decisão, tal como "alocar água para irrigar um determinado setor" ou pode ser uma quantidade afetada por essa decisão, e.g. "quantidade de água alocada."

Quando uma variável não é afetada por nenhuma das variáveis incluídas dentro do nosso sistema, ela será chamada de variável "exógena," ou simplesmente externa ao sistema. Uma variável que é influenciada pelos valores e mudanças de outras variáveis incluídas no sistema será chamada variável 
"endógena." Nos diagramas de loops de feedback as variáveis se representam simplesmente pelo seu nome, eventualmente inseridos dentro de uma caixa de texto.

Um vínculo é uma relação de causa-efeito ou de influência entre duas variáveis. Nos diagramas, os vínculos são representados por uma seta cujo início liga a variável considerada "causa" ao extremo oposto da seta que aponta na direção da variável "efeito" (ou variável que sofre a influência da variável causa). Assim, se estamos interessados em representar graficamente o fato de que a variável $\mathrm{A}$ influencia a variável $\mathrm{B}$, escreveremos :

FIG. 1

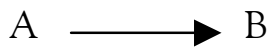

Quando existe conhecimento suficiente, podemos ser ainda mais precisos através do conceito de "sentido" de um vínculo. Diremos que um vínculo possui sentido "positivo" (FIG. 2A), se a um acréscimo no valor da variável causa corresponde um acréscimo no valor da variável efeito e, reciprocamente, a uma diminuição da variável causa corresponde uma diminuição da variável efeito.

FIG. 2A

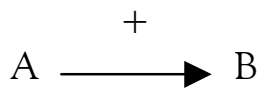

FIG. 2B

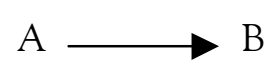

Diremos também que um vínculo tem um sentido negativo (FIG 2B) se a um acréscimo da variável causa corresponde um decréscimo da variável efeito (ou, se a um decréscimo da variável causa corresponde um acréscimo da variável efeito) . Indicaremos essa situação com um sinal - acima da seta. Isto é, se o sentido do vínculo é positivo indica que ambas variáveis mudam na mesma direção; o sentido é negativo quando elas mudam em direções opostas.

Um loop de feedback consiste em dois ou mais vínculos conectados de tal forma que, começando com uma variável qualquer do loop, pode-se, seguindo a direção das setas, retornar à variável de origem da trajetória. No exemplo da FIG. 3, o vínculo entre a variável $\mathrm{A}$ e a variável $\mathrm{B}$ tem sentido positivo, como está indicado pelo símbolo + junto à seta, significando que quando $A$ aumenta $B$ também aumenta e quando A diminui B também diminui. Entretanto o vínculo entre B e A é negativo, i.e. quando $\mathrm{B}$ aumenta $\mathrm{A}$ diminui ( $\mathrm{e}$ vice versa). 
FIG. 3

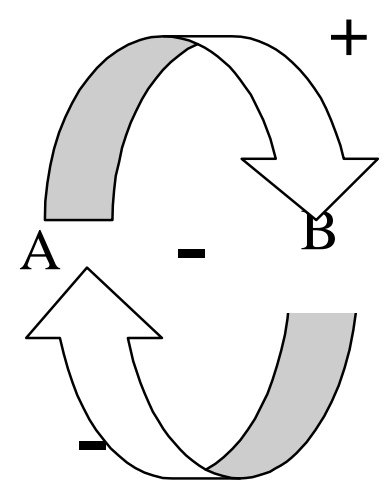

Exempo de sistema de feedback com três variáveis

FIG. 4

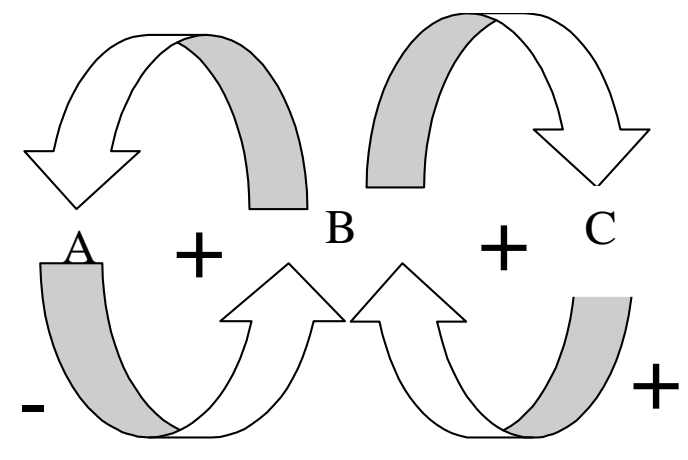

Neste exemplo as variáveis A e B formam um loop de feedback, as variáveis $\mathrm{B}$ e $\mathrm{C}$ formam outro loop e as três variáveis juntas formam um sistema de feedback.

Um outro conceito importante é o de "polaridade de um loop." A polaridade de um loop de feedback está determinada pela regra dos sinais (ou pela regra da multiplicação) dos vínculos que o compõem. A polaridade se representa, quando necessário, por um sinal no centro do loop. Na FIG. 3, o loop tem uma polaridade negativa, já que um dos vínculos que o compõem é positivo e o outro é negativo. Já os 
dois loops que compõem a FIG. 4 são positivos.

A FIG. 5 é composta de três variáveis: nível de poluição, preocupação com a poluição e controles. Três vínculos ligam as três variáveis, sendo que o vínculo entre "Nível de Poluição" com "Preocupação com a Poluição" tem um sentido positivo, o vínculo entre "Preocupação com a Poluição" e "Controles" é também positivo, enquanto que o vínculo entre Controles e Nível de Poluição tem um sentido negativo. Pela regra da multiplicação, o loop como um todo tem uma polaridade negativa (como indicado pelo símbolo no centro do diagrama).

FIG. 5

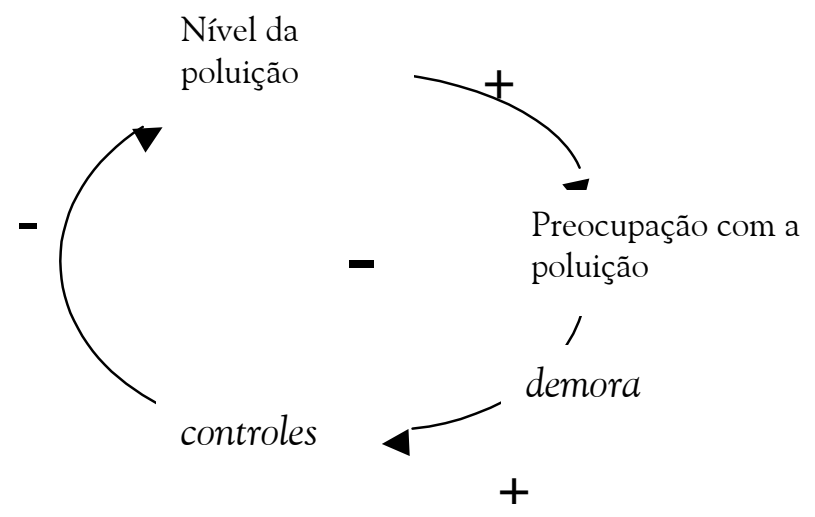

Os loops com polaridade negativa são também chamados de "loops de balanceamento." Eles induzem no sistema um comportamento oscilatório. Na FIG. 5, como o loop é de balanceamento, isto significa que quando o nível de poluição aumenta gera, por uma série de mecanismos que aqui não estão especificados, um aumento na preocupação com a poluição. Ao aumentar a preocupação com a poluição, executamse mecanismos de controle, que, por sua vez, determinam uma diminuição do nível de poluição. Os mecanismos de controle envolvem, geralmente, a elaboração e aplicação de legislação de proteção ambiental e a aplicação de medidas de prevenção ${ }^{17}$. Mas, uma diminuição no nível de poluição diminui (ou pode diminuir, se não se tomam os devidos cuidados) a preocupação com a poluição, o que por sua vez ocasiona uma diminuição das práticas de controle que levam a um aumento no nível de poluição, determinando assim uma dinâmica oscilatória no sistema.

\section{Um trágico caso real de feedback positivo}

Como mencionamos anteriormente, R. N. Mack e outros autores analisaram o efeito da invasão causada pelas gramas de tipo africano na floresta amazônica. Este tipo de grama foi importada para ser utilizada como alimento de gado. 
Elas têm como característica uma grande suscetibilidade ao fogo, e também a capacidade de ocupar rapidamente os espaços antes ocupados pelas árvores nativas destruídas pelo fogo.

Os autores advertem o extremo risco que esse ciclo de feedback positivo representa para o ecossistema global. $\mathrm{O}$ ciclo que caracteriza a ação da grama invasora segue a estrutura de FIG. 6:

FIG. 6

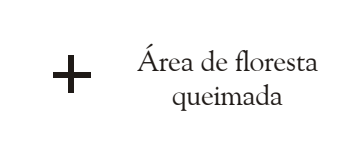

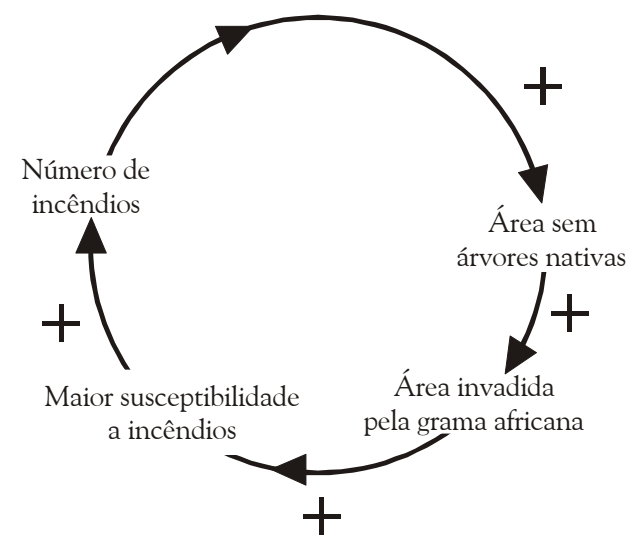

Um exemplo de aplicação de loops de feedback na área de Urbanismo: O trabalho de Maruyama

Num sistema com feedback negativo, o processo de feedback funciona para "cancelar" ou "negar" as mudanças. Mas alguns sistemas fazem justamente o contrário. Cada mudança retro-alimenta o sistema para causar mais mudanças. A nova mudança irá causar ainda mais mudanças, na mesma direção, e assim sucessivamente. Na maioria dos casos, alguma coisa acontece que quebra este ciclo. Este comportamento é chamado de "feedback positivo," porque amplifica e acrescenta qualquer distúrbio ao sistema. Um exemplo:

Para nosso relato, o trabalho de Magaroth Maruyama tem relevância em dois aspectos: seu valor histórico e, por outro lado, como um caso de aplicação do conceito de feedback para explicar um problema urbanístico. Os autores, que em seus primórdios aplicaram a dinâmica de sistemas para explicar fenômenos sociais, faziam parte quase que exclusivamente da herança dos ciberneticistas, que enfatizavam os 
loops de balanceamento ou loops de retroalimentação negativa esquecendo os loops de feedback positivos, ou loops de reforço. Foi precisamente Maruyama quem reconheceu o significado dos loops de feedback positivo -que ele chamou de processos de amplificação de desvios- em muitos fenômenos biológicos e sociais. Seu trabalho teve tanto significado que vários autores chamam o movimento iniciado por Maruyama de "Segunda Cibernética." Este autor descreve esses fenômenos assim:

\begin{abstract}
"Acumulação de capital na indústria, evolução de organismos vivos, a emergência de culturas de vários tipos, processos interpessoais que produzem doenças mentais, conflitos internacionais, e os processos que são chamados genericamente de "círculos viciosos" e de "juros compostos;" simplificando, todos os processos de relação causal mútua que amplificam um impulso inicial insignificante ou acidental, e que constrói acima dele desvios e divergências de suas condições iniciais." (MARUYAMA, 1963: 304)
\end{abstract}

Segundo Richardson ${ }^{18}$, um dos grandes méritos de Maruyama é o de enfatizar a propriedade que têm os loops de feedback positivos de amplificar um impulso inicial, que "pode ser um evento aleatório" e que poderia puxar o processo de auto reforço em qualquer direção. Um problema interessante, citado por Richardson e que Maruyama considerou a partir de sua perspectiva, constitui-se da proposta de Myrdal para economias em desenvolvimento:

\begin{abstract}
"Assim, em países economicamente subdesenvolvidos é necessário não somente planejar a economia, mas também dar o impulso inicial e reforçálo por um tempo em tal direção e com tal intensidade que possa ser atingida a maximização da eficiência do desenvolvimento causado por investimento inicial." (MARUYAMA, 1963: 305).
\end{abstract}

Entretanto, as idéias de Maruyama ${ }^{19}$ exibem mais claramente seu poder explicativo quando ele analisa o crescimento das cidades. Aqui ele sugere um padrão de auto reforço similar. A região na qual a cidade começa pode ser essencialmente homogênea, mas os primeiros estabelecimentos dão início a um processo que conduz à concentração de atividade no que eventualmente constituirá a cidade:

"O segredo do crescimento da cidade está no processo de amplificação de desvios -que constitui uma rede de processos de feedback mutuamente positivos- mais do que nas condições iniciais ou no impulso inicial. Este processo, mais do que as condições iniciais, tem gerado a complexidade da estrutura da cidade. É neste sentido ... o processo é chamado de morfogenêsis." (MARUYAMA, 1963: 167).

O sistema mostrado na FIG. 7 contem vários loops, alguns dos quais são de amplificação de desvios; outros são de balanceamento (neutralizadores de desvios). 
Para que o sistema como um todo se comporte como amplificador ou como balanceador de desvios, depende da força de cada um dos loops. Uma sociedade ou um organismo contém muitos loops amplificadores e muitos loops balanceadores, e uma compreensão da sociedade ou do organismo não pode ser atingida sem estudar ambos os tipos de loops e as relações entre eles.

FIG. 7

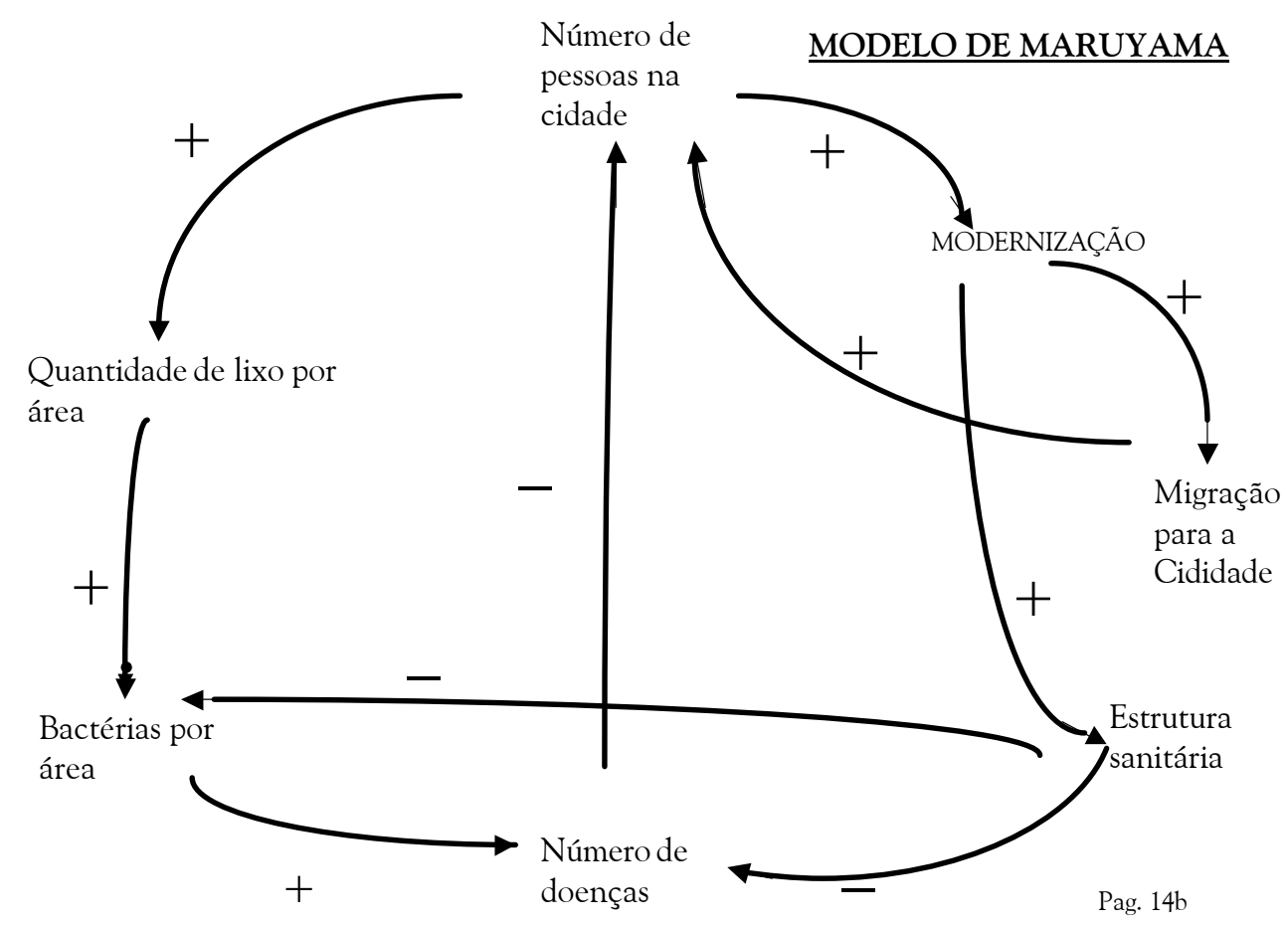




\section{ARQUÉTIPOS E ESTRUTURAS TRANSFERÍVEIS OU GENÉRICAS}

A idéia de estrutura transferível ou genérica é uma das mais importantes no Raciocínio Sistêmico. Ela permite entender o comportamento de sistemas de diferentes disciplinas através do entendimento do comportamento de sua estrutura genérica subjacente. Apesar da enorme variedade de sistemas, muitos deles têm alguns comportamentos semelhantes. Naqueles sistemas onde o loop dominante é de reforço, enquanto dure esta dominação, o sistema terá um comportamento de tipo exponencial. Sistemas tão diversos como: crescimento bacteriano (em suas fases iniciais), aquisição de conhecimento, juros compostos, etc. apresentam comportamentos similares. Isso se explica porque suas estruturas sistêmicas são similares, apesar da natureza dos elementos que os compõem serem totalmente diferentes.

No início da prática da Dinâmica de Sistema, os pesquisadores que tentavam construir modelos procuravam identificar cada um dos vínculos que poderiam explicar o comportamento do sistema. Isso fazia com que a associação de modelos a comportamentos observados de sistemas demandasse um enorme esforço. Hoje, dispõese de um conjunto básico de "estruturas genéricas," como são chamadas por J. Forrester, ou "arquétipos sistêmicos," como são denominados por Senge.

Cada um desses arquétipos representam um tipo de comportamento, comum a muitos sistemas. Na atualidade, existe uma dúzia de arquétipos de uso amplamente disseminado. Entretanto, um arquétipo pode dominar o comportamento "durante um tempo." Porém, em algum momento o sistema pode mudar de arquétipo dominante. Isso faz com que trabalhar com arquétipos sistêmicos signifique dois tipos de problemas: o da identificação e o da detecção da mudança. Aqui a disciplina mostra seu poder, oferecendo um conjunto de técnicas para lidar com estes dois problemas a partir da observação do comportamento das variáveis relevantes do sistema.

Os arquétipos mais comuns são: "limites ao crescimento," "tragédia dos comuns," "concertos que atrapalham," "crescimento e sub investimento" e "transferência de responsabilidade." Poder-se-ia estabelecer uma hierarquia de conceitos na Física partindo-se do elétron. Por analogia com a Física Atômica, poderíamos pensar que vem do conceito de loops de feecback (análogo aos elétrons, prótons e neutrons). A combinação dos loops formam as estruturas sistêmicas, ou arquétipos, como os elementos básicos formam os átomos. Analogamente, a combinação dos arquétipos determina a estrutura do sistema, como a combinação de átomos determina as moléculas, que, por sua vez, determina o comportamento do sistema.

Estruturas e comportamentos transferíveis podem criar uma ponte entre diferentes disciplinas científicas, especialmente entre as ciências sociais, economia e engenharia. Os loops de feedback são comuns a todas elas. Uma compreensão de uma estrutura sistêmica em uma das disciplinas permite a transferência do aprendizado a todas as outras. É nesse sentido que podemos considerá-las como formando a linguagem comum, tão demandada por Norgaard. Ciência, economia, populações biológicas e comportamento humano se apóiam, segundo Forrester, no mesmo tipo de estrutura dinâmica ${ }^{20}$. 


\section{Exemplos de arquétipo sistêmico}

\section{a) Limites ao crescimento}

A seguinte estrutura sistêmica, representada na FIG. 8, é chamada de "limites ao crescimento." Ele pode ser aplicado para descrever aspectos tanto da economia global como da economia de uma comunidade. Como vemos, a estrutura consiste de dois loops e um fator limitador. O primeiro loop é um loop de reforço, já visto anteriormente. $\mathrm{O}$ segundo é um loop de balanceamento, que tende a neutralizar os efeitos sobre o volume de output do primeiro loop. Uma interpretação profunda desta estrutura demandaria um conhecimento do contexto no qual ela opera. Porém, algumas afirmações podem ser antecipadas sem risco de erro. O loop de reforço domina a estrutura durante as primeiras etapas de funcionamento do sistema. Isso acontece quando os limites estão ainda muito distantes e, em conseqüência, são pouco operacionais. Mas, à medida que o tempo passa, a operação do sistema vai consumindo os recursos, e os limites vão tornando-se cada vez mais ativos. Isso significa que o loop de reforço se torna cada vez mais dominante, inibindo o crescimento. Duas situações são possíveis, dependendo de como o sistema é gerenciado, isto é, dependendo de outras forças que podem ser incluídas. Uma alternativa é chegar a um estado de equilibro, que é a proposta de Forrester. A segunda alternativa é o colapso total do sistema, que é o que Forrester quer evitar (e nós também).

FIG. 8

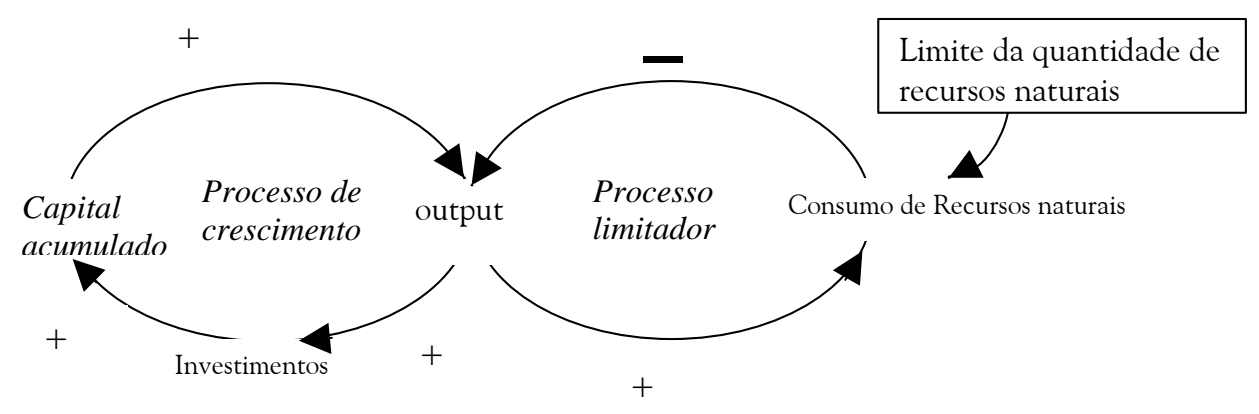

Sistêmico

b) Políticas na área de transporte público: outra aplicação de Arquétipos

No presente exemplo, considerarei um caso real descrito por Michel Goodman \& Karash (1995). Os autores analisam uma proposta do Departamento de Transporte sobre aumento na capacidade das estradas na cidade Newbury, Inglaterra, que gerou muita controvérsia entre os cidadãos do município . A proposta envolvia obras num total de 100 milhões de libras esterlinas. Os habitantes da cidade estavam 
divididos com relação à necessidade da construção prevista -os que contestavam a necessidade da obra mantinham a posição de que só $5 \%$ do trânsito deveria ser desviado para fora da cidade. Contrários a essa opinião, os representantes no Conselho Municipal afirmavam que as obras eram a única solução viável. A pergunta que tem sentido ser colocada, tanto do ponto de vista dos habitantes da cidade como de nosso ponto de vista pedagógico, é: "Porque mais e mais estradas poderiam não ser a solução do problema da congestão no trânsito?"” ${ }^{1}$ Um input necessário ao processo decisório seria a observação cuidadosa das variáveis relevantes ao problema e como elas se relacionavam ao longo do tempo.

Uma análise das variáveis envolvidas mostrava que o sintoma do problema -a congestão do trânsito- alternadamente melhorava e se deteriorava, enquanto sua dependência de soluções de curto prazo (mais estradas) era cada vez maior. Esse comportamento sugere a utilização do arquétipo sistêmico "transferência de responsabilidade," descrito pelo diagrama exibido na FIG 9. A leitura do diagrama foi feita da seguinte maneira. Partindo-se do meio do diagrama, notou-se que existia um evidente crescimento global da congestão de trânsito. Para lidar com esse crescimento, duas alternativas básicas eram possíveis: construir mais estradas, como era a proposta oficial, ou, por algum mecanismo, reduzir a dependência em transporte automotor. Construir mais estrada era a soluçao mais atraente (solução sintomática), entre outras razões porque isso significava um apoio importante à indústria da construção civil e, pelo menos a curto prazo, "dissipava o problema do trânsito." Esta solução cria um loop de balanceamento (1) -no sentido de que um aumento em congestão de trânsito tem um efeito positivo na construção de estradas, enquanto que a construção de estradas tem um efeito oposto -negativo- a curto prazo na congestão de trânsito.

FIG. 9 


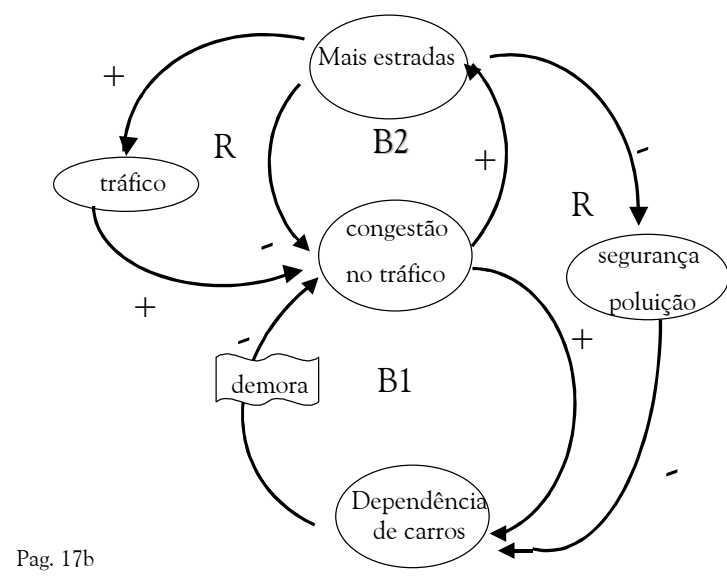

Estrutura sistêmica subjacente ao arquétipo "Transferência de responsabilidades"

A solução sintomática tem, entretanto, um efeito secundário, talvez desejado, ou não, para construir mais estradas. Ela produz um aumento da dependência do transporte automotor. Mais estradas significam menos segurança e conforto para pedestres e ciclistas, o que conduz a um aumento no uso de transporte automotor que, por sua vez, aumenta a congestão do trânsito que, por sua vez, reduz a segurança e o conforto de pedestres e ciclistas, criando assin um loop de reforço (3).

O Raciocínio Sistêmico nos ensina que, em situações de "transferência de responsabilidade," o poder de alavancagem das ações se focaliza em "soluções fundamentais." Somente diminuindo-se a dependência do transporte automotor poderse-á chegar a uma solução completa do problema.

\section{ECOSSISTEMAS: SEU ENTENDIMENTO E GESTÃO}

Nesta seção, serão mencionadas algumas características específicas do tema "Ambiente e sua Gestão," que servirão como ponto de partida de um caminho epistemológico e metodológico que culminará, naturalmente, na proposta de Raciocínio Sistêmico. Essas características indicam também o porquê do fracasso ao se tratar os ecossistemas com os métodos das ciências físico-químico e matemáticas. $\mathrm{O}$ processo geral de pesquisa nestas áreas assume a realidade como sendo uma entidade estruturada, e afirma que o conhecimento -e a conseqüente capacidade de prediçãofoi obtido uma vez que a estrutura, e suas partes, foram identificadas. Os resultados das pesquisas nestas ciências se validam por seguir uma metodologia cujo desenvolvimento se deve principalmente a Newton, a Galileo e, mais tarde, a Descartes. 
Os trabalhos de Galileo tiveram um impacto monumental na história da humanidade, mas nunca foram valorizados devidamente. Naquela época, a Igreja era dona da verdade absoluta. Aqueles que questionavam essas verdades eram queimados na fogueira. Entre essas verdades estava a de que a esfera celeste era feita de uma substância "perfeita", chamado éter. O Homem ocupava o centro da terra que, por sua vez, era o centro desse universo. A Igreja definia a natureza desse universo. Galileo questionou esse paradigma com a ajuda de um instrumento -que ele não inventou, mas que utilizou com genialidade- o telescópio. Suas observações o levaram a afirmar que "a lua era de rocha, de matéria; que não era perfeita nem imperfeita; era um objeto físico. ${ }^{22}$ Ensinou-nos, assim, que a natureza pode ser observada e entendida. Com isso, jogou a Igreja fora do templo da ciência, onde ela nunca voltou nem voltará a entrar. Galileo fundou a ciência experimental, integrando a observação da natureza e o raciocínio.

O método cartesiano aplica um enfoque estruturado de pesquisa segundo o qual a verdade pode ser atingida reduzindo toda questão a suas componentes mais simples e mais facilmente explicáveis e, mais tarde, reconstruindo a resposta à questão original adicionando as partes. Este processo (DESCARTES, 1962) assume, em primeiro lugar, que existe uma estrutura do Universo que pode ser descoberta por dissecção e reconstrução e, em segundo lugar, que o todo não é mais do que a soma de suas partes.

Newton, por sua vez, também desenvolveu uma visão estrutural do Universo ao descrevê-lo como um mecanismo do tipo relógio sujeito a leis altamente previsíveis. A utilização do processo de Galileo, do Método Cartesiano e do Modelo do Universo de Newton levou à crença de que o Universo estava sujeito às Leis Naturais da Ciência e que estas leis, uma vez descobertas, poderiam ser utilizadas para predizer o seu comportamento. A visão Newtoniana do Universo foi substituída, ou melhor, ampliada pelo desenvolvimento da Teoria da Relatividade e, mais tarde, pela Teoria da Mecânica Quântica.

Nos últimos séculos, o método das ciências naturais se mostrou altamente eficiente cada vez que foi aplicado a objetos inanimados, mas mostra grandes limitações quando se aplica a disciplinas que envolvem seres vivos, incluindo pessoas e populações (sejam elas humanas, de animais ou vegetais).

O método científico (das ciências naturais) pode hoje ser considerado como sendo baseado em três princípios fundamentais que o caracterizam: Reducionismo, Repetibilidade e Refutação. Através do Reducionismo, o cientista seleciona uma porção do mundo para pesquisar e realizar observações disciplinadas na forma de experimentos. Se os resultados dos experimentos são repetíveis (reproduzíveis), eles passarão a ser aceitos como sendo parte do corpo de conhecimentos. O progresso acontece na forma de uma seqüência de experimentos que visam testar (para destruir) hipóteses. Assim, o conhecimento científico em um determinado momento histórico pode ser considerado como sendo o acúmulo de hipóteses que ainda não foram destruídas ou refutadas.

O poder do método científico reside na replicabilidade dos resultados, o que transforma suas descobertas em "conhecimento público." A dimensão fundamental da refutabilidade, a replicabilidade dos resultados experimentais, apóia-se na hipótese 
de que o fenômeno pesquisado é, na frase de Keynes, "homogêneo através do tempo." É por isso que Keynes rejeitava a idéia de tornar a economia uma ciência "pseudonatural," justamente porque contrariamente às ciências naturais típicas, o material ao qual a economia é aplicada é, em muitos aspectos, não homogêneo ao longo do tempo.

O ponto mencionado por Keynes sinaliza brilhantemente uma das principais dificuldades com que se defronta o cientista social e o pesquisador de temas ambientais quando se propõe a fazer uso, em suas próprias pesquisas, de métodos bem sucedidos na área das ciências naturais. Mas, além da dificuldade, da falta de homogeneidade temporal do material próprio dos estudos ambientais -que inclui a componente social e, consequentemente o subsistema econômico- o pesquisador desta área se defronta com outro desafio. Ele não pode aplicar esquemas que se apóiem no reducionismo -recurso sempre disponível ao pesquisador das ciências naturais- que define os limites de validade do experimento, i.e., as características do subsistema onde o experimento acontecerá. Para garantir a replicabilidade do experimento, ele deverá levar em conta as características essenciais desse subsistema. Todavia, para entender o ecossistema, o cientista não está habilitado a aplicar a alternativa cartesiana de decompor o sistema estudado em componentes básicas, analisá-las e, mais tarde, derivar as características do sistema pelo conhecimento adquirido sobre suas partes e, finalmente, reconstruir o sistema através da soma das partes. A impossibilidade do cientista do meio ambiente de escolher os limites precisos e controláveis do sistema onde seu experimento acontecerá cria mais um grande obstáculo metodológico. Surge então a seguinte pergunta: pode o método das ciências naturais ser aplicado a um material que não é homogêneo ao longo do tempo e inserido em subsistemas não controlados pelo pesquisador, fazendo com que a replicabilidade completa seja impossível?

Se a resposta é não, que outra coisa pode ser feita? Talvez, o que pode ser feito esteja incluso e poderia ser derivado da dialética hegeliana que "considera as coisas em seu movimento e mudança, interações e interrelações. Tudo está em um contínuo processo de chegar a ser e de cessar de ser, no qual nada é permanente, mas tudo muda e eventualmente é substituído." Observemos que, com palavras próprias da filosofia, o que a dialética enuncia são as mesmas características presentes no conceito de sistemas complexos, em particular dos ecossistemas, às quais nos referimos acima.

Além dessas características, os fenômenos sociais e ambientais têm uma outra, também importante para a nossa proposta: a de que só pelo fato de pensarmos e argumentarmos socialmente a respeito deles, eles podem ser mudados (são entendidos com abstrações mentais ao meta-nível de sua manifestação). A estrutura do mundo físico, entretanto, não muda porque pensamos, argumentamos ou fazemos teorias a seu respeito. Este é o contexto no qual a "pesquisa da ação" (Action Research) surge com Kurt Lewin (1890-1947). Como os fenômenos sociais e ambientais são "não homogêneos no tempo, não são replicáveis, e são alterados pela participação do pesquisador" e pela "ação social," surge então a proposta de que a própria metodologia inclua a possibilidade da mudança como base da pesquisa.

Veremos nos próximos parágrafos que o Raciocínio Sistêmico é capaz de ocupar o espaço vazio deixado pelo método das ciências naturais, quando o objeto a ser 
estudado não permite satisfazer seus requerimentos metodológicos. A replicabilidade e/ ou repetibilidade encontrarão, através do Raciocínio Sistêmico, uma alternativa metodológica e epistemológica na transferibilidade das estruturas sistêmicas e na experimentação através de modelos. O roteiro metodológico proposto pela Action Research pode ser um caminho que garante a refutabilidade. Os recursos do Raciocínio Sistêmico para analisar a dinâmica dos fenômenos, através do pensamento dinâmico e de suas ferramentas, permitem também enfrentar situações que são "não homogêneas ao longo do tempo." O processo de construção de modelos e identificação de estruturas e arquétipos oferece um caminho para tornar público o conhecimento adquirido e fazê-lo, assim, "refutável."

As considerações anteriores são essencialmente de tipo metodológico, mas algumas preocupações de ordem prática também podem encontrar resposta -ou pelo menos alívio- no Raciocínio Sistêmico e em sua operacionalização. ${ }^{23}$ Dentro deste contexto, é fácil localizar, como exemplos, os fenômenos da globalização e do desenvolvimento sustentável na economia e do aquecimento global no ambiente. ${ }^{24}$ Assim, os problemas são graves porque são sistêmicos e, porque são sistêmicos, suas soluções só podem ser encontradas em disciplinas que sejam capazes de lidar com a complexidade sistêmica. Alguns destes temas serão apresentados nos próximos parágrafos, onde introduziremos uma forma de entender o Raciocínio Sistêmico. Os temas que ficarem pendentes serão dívidas para futuros trabalhos ou para contribuição de outros colaboradores da revista.

\section{O PENSAMENTO NO RACIOCÍNIO SISTÊMICO}

Ao longo dos tempos, desde que o homem começou a refletir sobre os problemas do universo que ele observava, filósofos elaboraram métodos ou propostas sobre "como pensar as coisas." Alguns deles criaram metodologias, e até procedimentos, para "pensar melhor." Naturalmente, juntamente com o problema de como pensar melhor, colocava-se a questão da "validade" do resultado da reflexão, o que deu origem às disciplinas da Lógica e da Epistemologia. A proposta dos diversos pesquisadores que desenvolveram o "Raciocínio Sistêmico" lida, essencialmente, com esses assuntos. Porém, no momento histórico em que estamos vivendo, consideramos outra questão também essencial, devido ao fato de fazermos parte de uma sociedade em rede, ou sociedade da informação. Trata-se da questão da disseminação e comunicação do conhecimento. Nessa linha, em relação aos ecossistemas, não podemos deixar de ressaltar a importância da educação ambiental, em todas as suas dimensões, como forma de implementar a "intencionalidade estratégica," cuja necessidade mencionamos na introdução deste artigo. Nesta tarefa, a comunidade acadêmica não pode ser substituída. Ao longo deste, e de futuros trabalhos, propomo-nos a discutir a forma em que o Raciocínio Sistêmico pode contribuir com as questões educacionais.

Antes de avançarmos mais fundo nestas questões, é recomendável descrevermos brevemente os elementos que compõem o Raciocínio Sistêmico e que caracterizam sua identidades e sua integridade, já que a expressão Raciocínio Sistêmico é utilizada com vários significados, alguns deles incompletos.

Em algumas ocasiões, esta disciplina é referida como sendo um "conjunto de 
ferramentas," tais como "diagramas de causa-efeito, diagramas de fluxos e acumuladores ${ }^{25}$, modelos de simulação, etc. Em outras ocasiões, ela é vista como "uma perspectiva" de análise da realidade, que inclui no objeto de estudo o "todo sistêmico" e a forma em que as partes do todo interagem umas com as outras. ${ }^{26}$ Alguns autores sugerem que, além das visões anteriores, o Raciocínio Sistêmico seja visto como "uma nova linguagem,]" de entendimento e comunicação de conceitos, principalmente aqueles derivados da apreciação de realidades que apresentem alto grau de complexidade dinâmica. Nenhuma das perspectivas anteriores está fora do escopo da disciplina. Mas, para organizar seus conteúdos, desmembraremos cada uma delas em duas dimensões não ortogonais: a dimensão dos níveis de entendimento da realidade, e a dimensão dos caminhos ou roteiros de aquisição e aplicação dos conhecimentos.

\section{A dimensão dos niveis de entendimento da realidade}

Existem muitas lentes através das quais podemos observar os fenômenos da natureza, cada uma com diferente capacidade de captação do todo ou os dos detalhes dos fenômenos observados. Isso leva à existência de vários níveis de entendimento, a partir dos quais podemos processar nossas observações e tentar assim entender o mundo. De uma perspectiva sistêmica, estaremos interessados em quatro níveis que, em ordem crescente de complexidade de percepção são: eventos, padrões de eventos, estruturas sistêmicas e valores e visões compartilhadas.

Eventos: são as coisas com que nos deparamos no dia-dia: um acidente, um incêndio na floresta, a morte de uma árvore, a migração de um indivíduo (humano ou não) de uma região para outra, etc. Nossos mecanismos de percepção os captam de maneira direta. Considerados isoladamente, eles nada nos informam sobre eventos similares.

Padrões de eventos: são as memórias acumuladas de eventos que se repetem em algum sentido. Quando os eventos se agrupam como uma série ao longo do tempo ou como conglomerados no espaço, podem revelar padrões de comportamento recorrentes. Os "padrões de eventos" podem ser vistos como os "geradores dos eventos," porque eles podem ser responsáveis pela produção dos eventos. Para identificar e analisar padrões, precisamos de algum recurso metodológico que não só identifique cada evento mas que também determine a associação de todos os eventos ao longo do tempo e/ou do espaço.

Estruturas sistêmicas: comunidades ecológicas e sistemas sociais podem ser vistos como organismos ligados entre si por uma rede de relações características de cada sistema particular. Estas relações entre os componentes do sistema -sua estrutura- determinam os padrões de comportamento do sistema. Deste ponto de vista, as estruturas sistêmicas podem ser entendidas como "geradoras de padrões de eventos" e, por caráter transitivo, responsáveis pela produzção dos eventos. As estruturas sistêmicas só se tornam aparentes, no nosso entendimento, através do uso de uma teoria da realidade sistêmica.

Visões Compartilhadas: agem, muitas vezes, como "geradoras de estruturas 
sistêmicas," já que elas constituem as forças orientadoras que operam por trás da criação e mudança de todo tipo de estrutura sistêmica.

Infelizmente, nós nos movemos num mundo -individual e social-cujos mecanismos cognitivos valorizam a orientação aos eventos. A maior parte do esforço de pesquisa se focaliza nos eventos, ou às vezes em seus padrões. Os eventos, quando representam problemas, caracterizam-se pelo requererimento de uma resposta rápida. Imaginemos que um incêndio se produz em uma determinada floresta. Tentar apagálo, evitar vítimas, socorrê-las, salvar animais, etc. são ações próprias de serem realizadas imediatamente. Entretanto, se esta é a "única" atitude que se toma, sob uma perspectiva sistêmica, ela será inadequada. Porquê? Porque o problema imediato pode ter sido resolvido (domínio e socorro), mas nada foi feito para alterar a estrutura fundamental que causou o evento. Pensar em termos de níveis de entendimento mostra como podemos passar de uma típica orientação a eventos e começar a olhar para ações de alavancagem de nível mais alto.

\section{Passando da "atenção ao incêndio para "a prevenção de incêndios"}

No caso de um incêndio, ou acidente, a ação mais apropriada e urgente é a de "atender as vítimas e evitar a disseminação de seus efeitos". O único tipo de resposta disponível na hora é a de tipo "reativo." Entretanto, se colocamos todos nossos recursos e energia para agir no nível do evento, estes poderão repetir-se com freqüência. Ao agirmos como "corpo de bombeiros" poderemos começar a analisar "o padrão de eventos" com a finalidade de antecipar quais são os lugares e dias em que estes acontecem com maior freqüência. Ao analisar a evolução ao longo do tempo, poderíamos saber se existe uma tendência crescente, se eles tendem a agruparse em torno de determinados assentamentos, etc. Poderemos, seguindo esta conduta, ser mais adaptativos, equipando adequadamente e colocando estações e postos de apoio nas áreas e épocas críticas. Estas decisões terão como base "a observação dos padrões que, no passado, apresentaram os eventos." Sendo adaptativos, seremos mais eficientes no auxílio em casso de desastres. Entretanto, nada de fundamental seria feito ainda para reduzir a freqüência com que os desastres acontecem.

Outras são as questões que nos colocamos quando atuamos ao nível das "estruturas sistêmicas." Que forma de vigilância está sendo operada? Como está sendo tratada a floresta? Houve alguma substituição de espécies nativas que tenha acontecido concomitantemente à modificação do padrão de eventos observados? Ações tomadas neste nível -e. g. recuperação da mata nativa- podem, de fato, reduzir a freqüência e a gravidade dos eventos. Elas são "criativas," porque visam criar um futuro diferente. Assim, trabalhar no nível da estrutura sistêmica oferecenos a chance de uma maior capacidade de alavancagem. Porém, para mudar as estruturas sistêmicas, é preciso, geralmente, ações mais demoradas.

Poderíamos colocar perguntas num nível ainda maior. De onde vêm as estruturas sistêmicas? Como elas se originam? A resposta é que as estruturas sistêmicas são o reflexo de visões compartilhadas sobre quais são os "valores desejados." Neste 
caso, quanto a sociedade e o governo valorizam nossas florestas? Quanto as pessoas se envolvem na luta por salvá-las? Qual o significado que o ecossistema tem para o sistema capitalista? Ao nível dos "valores compartilhados" ou "visões compartilhadas" nossas ações podem ser "generativas", no sentido de que elas criam as condições para que as coisas desejadas venham a existir.

É importante salientar que o processo de aquisição de uma compreensão profunda da realidade não é linear (i.e., não vai direto do evento à visão compartilhada). Nosso entendimento da situação, num determinado nível, pode retro-alimentar e enriquecer nossa percepção em outro nível (inferior ou superior). Para ser mais efetivo, todos os níveis devem ser considerados simultaneamente. $\mathrm{O}$ risco é de que, ao operar em um nível, os outros venham a ser esquecidos. Entretanto, nossa habilidade de influenciar os sistemas e criar o futuro aumenta significativamente quando nos movemos do nível de eventos ao nível de visões compartilhadas. Mas poderíamos questionar se as ações de alto poder de alavancagem só podem ser encontradas nos níveis superiores. A resposta é não. O conceito de "alavancagem" é relativo, e não absoluto. Quando um incêndio está acontecendo, a ação de maior alavancagem é tentar apagá-lo, ou evitar sua disseminação. Qualquer outra ação é inadequada. Quando nos movemos dos eventos às visões compartilhadas, o foco se desloca de uma "orientação para o presente" para uma "orientação para o futuro." Como conseqüência, as ações tomadas nos níveis superiores terão mais impacto nos resultados futuros, e não nos eventos presentes.

Trabalhar com uma perspectiva clara sobre em que nível de entendimento queremos adquirir conhecimento tem uma repercussão significativa sobre como adquirimos informação, i. é., sobre quais serão os métodos de pesquisa, a quantidade e o tipo de dados e as técnicas de processamento da informação mais adequadas para nosso enfoque. Assim, se queremos conhecer um padrão, o tipo de dados e a forma de processálos devem ser adequados. Neste caso, uma tabela não será a melhor forma de apresentar os dados, já que ela apenas enumera os eventos sem considerar a ordem, impossibilitando a identificação da componente temporal. Entretanto, ela pode conter os dados necessários para comparar freqüências. Da mesma forma, uma manipulação inadequada de metodologias de identificação de padrões, ou uma avaliação imprópria destes, impede a correta identificação de estruturas sistêmicas.

\section{A Segunda dimensão: os caminhos e as habilidades do Raciocínio Sistêmico}

A limitação da linguagem -e da lógica que praticamos- leva-nos a realizar uma descrição de cada uma das habilidades separadamente. Às vezes, ao descrevermos cada uma delas, é mais efetivo, do ponto de vista pedagógico, indicar "o que não é Raciocínio Sistêmico" para melhor caracterizar "o que é." Entretanto, enfatizamos que é o uso integrado destas habilidades que dá valor conceitual, prático e metodológico à disciplina. ${ }^{27}$

1.- O caminho do pensamento dinâmico: 
O pensamento dinâmico coloca as questões e os temas em termos de padrões de comportamento ao longo do tempo, e é a partir desse ângulo que procura sua formatação e entendimento, sugerindo-nos a parcialidade em que podemos cair se nos focalizamos unicamente nos eventos isolados. Assim, por exemplo, no tema relativo aos vazamentos de óleo, o pensamento dinâmico nos leva a focalizar nossa análise não só na causa especifica que gerou determinado acidente -para a qual sempre haverá uma justificativa técnica tardia, complicada e pouco interessante, e sobre a qual já não poderemos fazer nada- mas no fato de que estes acidentes se repetem com uma trágica freqüência. Aqui, uma forma sistêmica de pensar o problema colocaria em evidência que as causas que determinam o padrão dos acidentes estão em métodos e pressupostos gerenciais sobre os quais nosso posicionamento cívico pode influenciar.

O Raciocínio Dinâmico, através de vários instrumentos, desenvolve a capacidade de analisar os padrões (principalmente os de longo prazo) que explicam os eventos individuais. Por exemplo, o pensamento dinâmico e suas ferramentas permitem afirmar, através da análise de uma série temporal, que os vazamentos de óleo no Porto de São Sebastião constituem um problema sistêmico, e poderíamos também concluir que nada foi feito para resolvê-lo.

\section{2.- A habilidade de apreciar o sistema como um "conjunto de causas"}

Talvez seja mais fácil explicar o que significa apreciar o sistema como um conjunto de causas raciocinando através do complemento, i.e. explicando o significado de apreciar um sistema como um conjunto de efeitos. Nesta última perspectiva, o desempenho do sistema é atribuído a forças que ficam fora do sistema e, em conseqüência, fora do controle dos gestores e atores do sistema. A perspectiva de apreciar o sistema como um conjunto de causas coloca nas mãos destes atores e gestores a possibilidade e a responsabilidade de examinar e determinar o conjunto de relações que causam o comportamento do sistema, estudar a relevância de cada uma delas, alterar o conjunto de relações para mudar sua estrutura interna com a finalidade de forçá-la a seguir uma trajetória mais próxima da desejada, ou uma trajetória em que as forças externas gerem efeitos negativos menos destrutivos.

Do ponto de vista operacional, escolher a perspectiva de sistema como um conjunto de causas nos leva a nos focalizarmos no esforço de definir os limites do sistema a partir de sua governabilidade. Isso traz como conseqüência o fato de que nós, enquanto operadores ou gestores do sistema, aos efeitos da modelagem, entendida no sentido amplo, devemos deixar fora do sistema aquelas variáveis e aquelas relações que não estão sob nosso controle. Nossa missão consistirá assim em definir e manipular as variáveis sob nosso controle para conduzir o sistema na direção desejada. Observemos que esta perspectiva se contrapõe àquela que define o sistema como um conjunto de efeitos pois esta última nos coloca numa situação de impotência por sugerir nossa incapacidade de modificar ou orientar o sistema, induzindo-nos a agir como se nada pudéssemos fazer perante a força de suas relações.

A perspectiva de ver o sistema como conjunto de causas nos coloca diante 
de um imperativo moral e existencial: entregarmo-nos às forças externas, geralmente forças do "mal," ou elaborarmos estratégias individuais e coletivas para destruir e neutralizar essas forças, isto é, construir a história que desejamos. Entretanto, isso não deve ser interpretado como um convite a uma atitude voluntarista, mas sim um convite a uma atitude proativa, que nos leva a pensar, no caso dos ecossistemas, em todas as estratégias, análises, alianças, ações individuais e coletivas e metodologias que serão necessárias desenvolver para preservar o ecossistema.

Um exemplo que mostra a importância do desenvolvolvimento da habilidade de apreciar o sistema como um conjunto de causas, e que nos serve como modelo, é O Caso das Cooperativas Industriais de Mondragón. A região norte da Espanha era, após a Segunda Guerra Mundial, uma das mais pobres e menos desenvolvidas do país. Lá existiam essencialmente duas fontes de renda: o trabalho artesanal feminino e uma velha fábrica de fogões. Sem nenhuma tradição cultural ou infra-estrutura industrial, a região não interessava aos investimentos americanos do pós-guerra. Vendo o sistema econômico local como um conjunto de efeitos, isto indicava que o futuro não podia ser mais sombrio para os habitantes da região. Entretanto, orientados por um líder com clara visão do futuro, o Padre Arizmendi, eles conseguiram transformar a região em uma das mais prósperas da Europa, com uma altíssima qualidade de vida e uma das melhores distribuições de renda do mundo. Isto foi possível através de um processo de reorganização social e do desenvolvimento de técnicas criativas de gestão, onde foram exploradas as possibilidades das relações internas ao sistema, o que implicou numa visão do sistema como conjunto de causas. Talvez o mais interessante é que a estrutura básica das cooperativas ${ }^{28}$ foi mantida. Os gestores do proceso tiveram a habilidade de modificar o conceito de cooperativa a ser aplicado, o que foi um dos principais fatores de sucesso. Ao invés do conceito de cooperativas de consumo, o conceito de cooperativas aplicado foi o de cooperativas de produção, sem deturpar suas idéias de base. Na linguagem do Raciocínio Sistêmico, poder-se-ia dizer que os gestores selecionaram um conjunto de variáveis internas, analisaram suas interrelações e encontraram os pontos de alavancagem para conduzir o sistema (a economia local) na direção desejada. As forças externas (negativas) foram neutralizadas ou transformadas em fatores favoráveis ao processo.

Infelizmente, o fenômeno Mondragón não é muito conhecido nem aplicado em nossa realidade política. Na maior parte dos casos, aceita-se principalmente aqueles que querem eliminá-la e que trabalham para isso- que a miséria resulta de fatores externos que, evidentemente, estão fora do controle dos atores e gestores do sistema. O modelo mental diz que é melhor rezar e depender da benevolência de seres supra- terrestres do que entender e tomar posse do próprio destino.

Sem dúvida, o leitor poderá encontrar uma grande variedade de pequenos e grandes exemplos das duas formas de apreciar os sistemas, bem como suas conseqüências. As oportunidades que apresentam essa mudança de perspectiva, quando aplicadas aos problemas ambientais, são, sem dúvida, de grande significado prático. 


\section{O PENSAMENTO ATRAVÉS DE MODELOS}

Os pesquisadores que lidam com ecossistemas, consciente ou inconscientemente, elaboram modelos que representam os sistemas de seu interesse. Esses modelos podem ser mentais, verbais, lógicos ou matemáticos, com alto ou baixo grau de sofisticação técnica e de formalismo. Porém, não é difícil constatar que, ao construir os modelos, o especialista fica muitas vezes prisioneiro de sua própria obra construída, passando com freqüência a confundir o modelo com o sistema real. Ao fazer isso, ele deixa de admitir que o caminho que a ciência e o conhecimento seguem não é o de provar verdades, mas o de rejeitar falsidades. Porém, em boa medida, o esforço intelectual dos especialistas que utilizam modelos nem sempre segue este caminho, principalmente quando orientados a provar que determinados modelos são "verdadeiros ou válidos." É por isso que "metodologias de validação de modelos" são citadas nas referências de trabalhos técnicos. Segundo esses especialistas, o modelo fica validado quando passa por critérios incluídos por eles mesmos. Como conseqüência desta linha de pensamento, considera-se que um modelo declarado válido é capaz de realizar predições precisas sobre o futuro. A capacidade de realizar predições passa a ser, segundo esta forma de pensar, um mérito hipotético e, ao mesmo tempo, o objetivo fundamental da construção do modelo. Essa pretensão, e consequentemente esse uso, constitui o foco de nosso questionamento.

A supervalorização da capacidade de predição dos modelos deriva do fato de todos nós termos um desejo irracional de conhecer de forma precisa o futuro. Isso nos leva a ser clientes potenciais das mais diversas formas de predição, que vão desde búzios e horóscopos a complexos programas de computação. Onde existe uma demanda logo aparece a oferta. Muitos acadêmicos fazem carreira desenvolvendo esses métodos. ${ }^{29}$ Entretanto, para que um modelo sirva de base para produzir predições precisas e confiáveis em sistemas ecológicos, organizações, mercados ou economias nacionais ou regionais, ele deve satisfazer algumas condições. Uma, a de ser completo, i.e., incluir todas as variáveis relevantes do sistema. Em segundo lugar, a de ser uma representação precisa da realidade. Todavia, para que o modelo possa ser utilizado como instrumento de gestão, uma terceira condição deve ser satisfeita: os tomadores de decisões, isto é, aqueles que supostamente utilizarão as predições realizadas com o modelo para definir suas políticas, devem reconhecer o modelo como sendo completo e uma representação fiel da realidade.

Porém, com relação a sua capacidade predictiva, uma quarta condição a mais ignorada- torna-se a mais relevante: a de incluir, na própria estrutura do modelo, a mudança das relações estruturais. A estes requisitos de ordem prática, que obviamente nunca são satisfeitos, agrega-se outro, de ordem conceitual: a observação da realidade é influenciada pela posição do observador. Esse princípio, oriundo da Física, vale também para os sistemas. Isso torna impossível a representação de qualquer realidade com a precisão necessária para fazer predições confiáveis.

Para que não pareça ao leitor que existe uma posiçao pessoal do autor contra a utilização e o propósito dos tipos de modelos antes mencionados -fenômeno 
freqüente em econometria e, por contaminação, em ecologia- lembremos o tão citado parágrafo de Wassily Leontief, Prêmio Nobel em Economia, sobre este tema:

\begin{abstract}
Year after year economic theorists continue to produce scores of mathematical models and to explore in great detail their formal properties; and the econometricians fit algebric functions of all possible shapes to essenctially the same set of data without being able to advance, in any perceptible way, a systematic understanding of the structure and the operations of the real economic system. (LEONTIEF, 1982: 107)
\end{abstract}

Muitos questionamentos metodológicos e epistemológicos poderiam ser feitos ao tipo de raciocínio que está por trás dos métodos de construção e validação dessa forma de utilização de modelos, que aqui chamaremos, sem pretender universalizar a denominação, de "raciocínio correlacional." "30 Entretanto, deixaremos o encargo (e o compromisso) da discussão e da crítica do raciocínio correlacional e de uma avaliação mais completa do uso de modelos baseados nesse conceito para um futuro trabalho. (Esclarecemos, desde já, que admitimos que este tipo de trabalho pode ter um grande valor e importância desde que sejam respeitadas algumas premissas).

O leitor poderia perguntar, a esta altura do texto, como é possível que, da mesma fonte que surge a proposta de se pensar em termos de modelos, levantam-se críticas tão acirradas ao que hoje constitui o que poderíamos chamar de paradigma dominante da utilização de modelos. Qual é a proposta do Raciocínio Sistêmico para substituir esta forma de uso de modelos? Este será o tema do nosso próximo parágrafo.

A perspectiva do Raciocínio Sistêmico será chamada de "Raciocínio Estrutural.” Este enfoque não se propõe a utilizar o modelo com o objetivo de realizar predições exatas, e sim com outros propósitos. Em primeiro lugar, como um instrumento de aquisição de conhecimento sobre as estruturas sistêmicas que determinam o comportamento do sistema real. Em segundo lugar, propõe-se a criar, de maneira sistemática, confiança na utilidade do modelo e atribuir a este o papel de instrumento para o processo de desenvolvimento de perspectivas sobre como melhorar o desempenho do sistema. Isso significa que, para o Raciocínio Sistêmico, o modelo é utilizado como parte de uma heurística (e não de um "algoritmo") destinada a melhorar o desempenho do sistema, o seu conhecimento e sua governabilidade.

O caminho do "goodness of fit" ${ }^{11}$, próprio do pensamento correlacional, é substituído aqui pela apreciação do modelo através de duas de suas dimensões: sua estrutura e sua robustez. Ao apreciar a estrutura, nossa preocupação se orienta a discernir quando e em que grau a estrutura do modelo se corresponde com a estrutura da realidade que o modelo pretende representar, que chamaremos de "estrutura sistêmica." Nestes processos surgem perguntas do tipo: existe correspondência entre a estrutura física do sistema real e a correspondente infraestrutura do modelo? A outra dimensão, a robustez, aparece quando nos perguntamos como o modelo construído se comporta quando mudam as condições, principalmente quando ele é colocado em 
funcionamento sob condições que se modificam ao longo do tempo ou que inicialmente poderiam ser consideradas extremas. Se o comportamento do modelo sob essas condições se afasta do comportamento do sistema real, diremos que o modelo não é robusto.

Aries P. de Geus (1988) afirma: “... através dos modelos de computadores damos a eles (cientistas e administradores de sistemas) um "brinquedo" -uma "representação do mundo real" da forma em que eles o entendem- com o qual eles podem "brincar," isto é, com o qual eles podem experimentar sem temer as conseqüências." O próprio de Geus menciona o trabalho de John Holt e Seymour Papert no Tavistock Institute onde eles mostram que, no processo de brincar com uma representação do mundo real, as crianças mudam sua compreensão do mundo -elas transitam para uma fase superior de desenvolvimento- elas aprendem. $\mathrm{O}$ autor continua “...estes princípios funcionam também para adultos.....a utilização de simuladores de vôo para pilotos, plantas pilotos para engenheiros em processos químicos, ou modelos de fluxo para engenheiros hidráulicos ...são alguns exemplos de representações do mundo real nos quais os pilotos e engenheiros podem experimentar sem temer pelas conseqüências. No processo eles aprendem, e só então aplicam na prática, seu novo, e agora confirmado, entendimento dessa parte do mundo, aceitando a responsabilidade pelas suas ações." A preocupação de de Geus é de que, quando os gestores de sistemas não têm a oportunidade de experimentar com modelos, eles experimentam com a realidade, muitas vezes com resultados desastrosos.

Podemos resumir nosso ponto de vista sobre modelos -e sobre simulação por computador utilizando modelos- afirmando que: os modelos devem capturar os "modelos mentais" (a serem introduzidos no próximo parágrafo) e o conhecimento dos responsáveis pela definição de políticas. Os modelos devem misturar mapeamentos qualitativos e simulação. O propósito deles é o de apoiar reflexão e aprendizado de grupos. Eles devem facilitar o pensamento sistêmico e o planejamento por cenários. As simulações devem mostrar histórias consistentes sobre o futuro, mas não predições. Eles são também micromundos, microcosmos da realidade, ambientes de aprendizado, que os cientistas podem usar para testar, desafiar e refinar seus próprios modelos mentais. 32

\section{O ROTEIRO DOS MODELOS MENTAIS}

Neste parágrafo, gostaríamos de colocar algumas evidências que provam que, contrariamente aos pressupostos de muitos cientistas preocupados com o meio ambiente, o enfoque do Raciocínio Sistêmico privilegia, mais que qualquer outro, a consideração de valores, ideologias e crenças. Essa inclusão é feita de maneira sistemática, utilizando-se, para isso, do conceito de modelos mentais e de sua inclusão estruturada como variáveis nos modelos que o praticante do Raciocínio Sistêmico constrói, sejam eles complexos e formais -através de computadores e programas de simulação- sejam eles simplesmente diagramáticos. Como conseqüência dessa valorização, esse conceito foi foco de atenção de todos os pesquisadores da área, desde as origens da disciplina. 
Senge dá tanta importância aos modelos mentais na disciplina do Raciocínio Sistêmico que ele os chama de "A Segunda Disciplina." Em seu livro, ele coloca o seguinte comentário: "Acreditamos cada vez mais que as causas ...destes insucessos não são intenções medíocres, propósitos excitantes ou mesmo pensamentos não-sistêmicos, mas sim os modelos mentais. Mais especificamente, os novos insights não chegam a ser colocados em prática porque conflitam com imagens internas profundamente arraigadas sobre o funcionamento do mundo, imagens que nos limitam a formas bem conhecidas de pensar e agir. Por isso, trazer à tona, testar e aperfeiçoar nossas imagens internas sobre o funcionamento do mundo, promete ser uma importante revolução ...”

Doyle e Ford (1998) argumentam que existem várias definições de modelos mentais, nem todas consistentes com o uso do conceito. Eles chegam à seguinte definição que, segundo esses autores, é a que melhor capta seu significado dentro do contexto do Raciocínio Sistêmico: "Um modelo mental é uma representação conceitual interna, relativamente estável, acessivel mas limitada, de um sistema externo, cuja estrutura contém a estrutura percebida do sistema externo."

Assim, na prática da disciplina, os modelos mentais podem (e devem) ser explicitamente incluídos nos modelos que estão sendo construídos e/ou testados com o objetivo de representar determinadas realidades sistêmicas. Para isso, os pesquisadores envolvidos na tarefa de construir estes modelos, qualquer que seja seu grau de sofisticação, devem se propor como primeira atividade tornar explícitos os modelos mentais dos próprios pesquisadores e os daqueles que serão atores do cenário onde o modelo será operacional, sejam estes gestores, elementos das comunidades e organizações envolvidas ou do próprio público.

Podemos tomar como exemplo do impacto que a negligência na consideração dos modelos mentais ocasiona na vida real o caso divulgado pela mídia em que agentes de uma ONG preocupada com o ambiente tentaram, com as melhores intenções, evitar algumas formas de exploração de madeira na Amazônia. Eles foram violentamente rejeitados pelos próprios atores locais, que os consideraram inimigos. Se tivessem sabido interpretar os modelos mentais dos atores locais, talvez isto não tivesse acontecido.

A segunda tarefa dos pesquisadores é encontrar uma maneira de incluir os modelos mentais, depois de explicitá-los, nos modelos de representação ou de simulação. Nesse sentido, a experiência mostra que essa atividade gera um subproduto importante: a própria representação ajudará aos pesquisadores a avaliar a importância e o efeito dos diferentes modelos mentais (inclusive os próprios modelos mentais dos pesquisadores) no comportamento do sistema. Uma terceira tarefa é a de construir e disseminar modelos mentais compatíveis com o comportamento desejável do sistema. Esta última tarefa é essencialmente educativa. ${ }^{33}$ Uma das maiores dificuldades no processo de educação são justamente as grandes diferenças que existem entre os modelos mentais dos especialistas e os das outras pessoas participantes de um processo de intervenção sistêmica -os atores. Algumas destas diferenças, que vale a pena registrar, são: o público, tomadores de decisão e atores em geral enfocam os problemas através 
do mecanismo de pensar por analogia, enquanto que os pesquisadores se preocupam com a quantificação, a especificação e o ajuste com as teorias por ele manejadas. Os outros atores se focalizam no teste oferecido pela realidade, enquanto os pesquisadores se preocupam com a concordância com a literatura e as pesquisas na área. Os atores se preocupam com o impacto em suas respectivas comunidades; os cientistas com a comunicação com os outros cientistas. Os atores se preocupam com a utilidade; os cientistas com o rigor científico de sua participação. Para os atores, o importante é a aplicação dos conceitos; para o cientista o importante é o desenvolvimento de teorias. ${ }^{34}$

Arriscamos a opinião de que os cientistas dedicados ao estudo da área ambiental encontram nestes modelos mentais e nos paradigmas dominantes no ambiente onde eles se desenvolvem -principalmente na área acadêmica- a principal camisa de força que os inibe de realizar ações mais efetivas. Nestas áreas, os cientistas são avaliados não tanto pelo benefício que seu trabalho intelectual traz para a humanidade quanto pelo número de trabalhos que ele consegue publicar. Este último propósito pode ser válido, mas é apenas um meio de comunicação, avaliação e monitoramento de seu trabalho. Eles esquecem que o propósito final é produzir conhecimento útil.

Todos esses modelos mentais são implícitos, às vezes inconscientes, e quase sempre negados, principalmente pelos acadêmicos. Entretanto, eles são tão ou mais operacionais que qualquer outra variável importante do sistema. Consequentemente, trazê-los à tona e incluí-los explicitamente no modelo, como variáveis, e não como fatores clandestinos, através dos diagramas de causa e efeito, representa um fator importantíssimo para que suas intervenções e seu trabalho social sejam bem sucedidos.

Infelizmente, nenhuma destas tarefas representam desafios fáceis de serem realizados. A boa noticia é que o Raciocínio Sistêmico oferece um contexto adequado e técnicas que facilitam sua realização. Nenhuma outra disciplina oferece tantas oportunidades para lidar com esse material de forma explícita e estruturada. Eu particularmente acho que esta é uma área de pesquisa ainda virgem e de grande potencial de uso prático.

\section{A SAGA DO RACIOCÍNIO SISTÊMICO}

Embora mais do que vestígios de conceitos sistêmicos podem ser detectados em pensadores do passado ${ }^{35}$, para nós, o momento do estabelecimento da escola de Raciocínio Sistêmico se deu com os trabalho de J. Forrester e de seu grupo, que culminaram com a publicação dos modelos World2 (1970) e World3 (1972), que se referem à gestão global do planeta. Concomitantemente com a apresentação dos modelos, foram publicados os seguintes livros sobre o mesmo tempo: World Dynamics ${ }^{36}$, The Limits to Growth ${ }^{37}$, e Beyond the Limits ${ }^{38}$.

A proposta básica que J. Forrester pretendia implementar através destes modelos é, em suas próprias palavras: "to avoid overshoot and sub-sequent decline in the global economic and population system it would be necessary to establish population and physical prodution at levels that are consistent with the limited enviromental carrying capacity of the planet Earth." 
Para cumprir com este propósito, Forrester desenvolve e utiliza a metodologia da Dinâmica de Sistemas que, desde esse momento, passa a ser o instrumento essencial da heurística do Raciocínio Sistêmico. O autor esperava - e em grande parte conseguiu-formular um novo paradigma em matéria de desenvolvimento econômico: o "equilíbro." ${ }^{39}$ Seria ousado de nossa parte tentar fazer uma análise que seja simultaneamente resumida e completa, tanto destes modelos como de seus respectivos impactos. A metodologia, como vimos anteriormente, manipula idéias relativamente simples, mas o conjunto requer maestria e aprofundamento. Apesar desta advertência nos arriscaremos a fazer alguns comentários com a finalidade principal de abrir campos de discussão e de estimular novas pesquisas:

Os modelos de Forrester estão constituídos por vários loops de feedback. Entretanto, existe um loop dominante-i. é., que determina essencialmente o comportamento do sistema- que é chamado de "loop central." Isolado dos outros loops, ele tem a forma simples mostrada na FIG. 10 e, como podemos constatar, trata-se de um loop de feedback positivo. Esse loop, ao definir a estrutura sistêmica que impulsiona o crescimento exponencial do output econômico ${ }^{40}$, de uma ou outra maneira, rege teoricamente quase todas as propostas de desenvolvimento econômico, capitalistas ou não.

FIG. 10

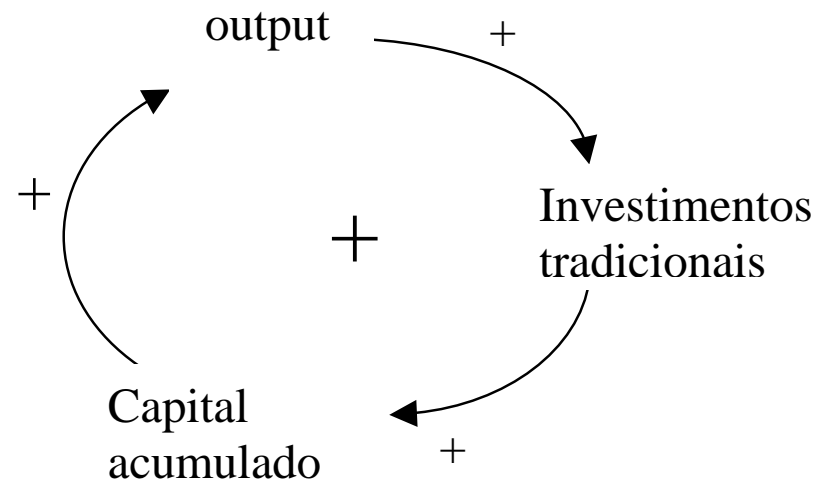

Forrester pensou que a dinâmica imposta por este loop poderia ser neutralizada -pelo menos em parte- por um loop, como o mostrado na FIG. 10A, que gerasse uma dinâmica de balanceamento, isto é, que tendesse a recuperar o equilíbro. Ele esperava que países e pessoas que atingissem um alto nível de padrão de vida (medido pelo consumo per capita) teriam menos interesse no crescimento do output econômico, o que, consequentemente, diminuiria a força impulsora por mais crescimento. Ao supor que este loop seria ativo, ele se baseou em um pressuposto errado e, em consequência, antecipou uma predição que se provou também errada. Segundo a predição de Forrester, a diminuição do impulso ao crescimento aconteceria após a duplicação da renda per capita real. O loop da FIG. 10A funcionaria assim: 
“..."padrão de vida," quando aumenta determina diminuição do "desejo por mais crescimento", que por sua vez determinaria menor "output", que por sua vez determinaria menor "consumo", que por sua vez determinaria uma queda no "nível de vida" ..."

Como vemos, na forma em que foi definido por Forrester, o loop é de balanceamento (três vínculos positivos e um vinculo negativo - aquele que vai de "padrão de vida" a "desejo por mais crescimento"). Obviamente, o vínculo foi definido por Forrester como sendo negativo porque nisso ele refletiu seu próprio modelo mental. Alguns colegas e discípulos de Forrester introduziram uma modificação importante neste último loop. Eles argumentaram que, contrariamente ao pressuposto de Forrester, quanto mais alto for o padrão de vida de uma sociedade ou de um indivíduo, maior é seu desejo por mais crescimento. Segundo estas considerações, o que puxa o desejo de consumo (e consequentemente, de crescimento) é "o nível de consumo do vizinho"; ou, em outras palavras, "o status" 41 . Assim, quanto mais status uma pessoa tem, mais status ela procura (através do consumo) ${ }^{42}$. Este altera o vínculo, que antes era negativo e passa a ser positivo, transformando-se no loop da FIG. 11B, composto por quatro vínculos positivos, definindo um mecanismo de feedback positivo, que vem reforçar o loop da FIG. 10, frustrando dessa maneira a expectativa de Forrester.

Tudo parece indicar que o fracasso de Forrester em encontrar paliativos para a dinâmica (positiva) do loop central -descrito na FIG.10 - reside em causas mais profundas do que o comportamento dos consumidores. Observando com cuidado o loop da FIG. 10, podemos verificar que ele representa a "própria dinâmica de acumulação capitalista" (!!). Isso significa que toda a lógica do sistema está representada nesse loop. Consequentemente, não devemos banalizar essa estrutura; para identificála, caracterizar seus componentes, e colocá-la no centro da dinâmica capitalista como um todo, foi necessário que um gênio como Mark gerasse uma das obras mais monumentais produzidas pela intelecto humano. Entretanto, o que nos interessa, do ponto de vista da gestão dos problemas ambientais em seus aspectos tanto globais como locais, é que -como acabamos de descrever-existem duas poderosas estruturas que devem ser levadas em conta no macro processo de gestão ambiental: a dinâmica capitalista e o comportamento dos consumidores. Daí a necessidade, sugerida nos primeiros parágrafos, de definir uma intencionalidade estratégica que guie nossas ações. No processo de desmembramento estratégico devemos considerá-las individualmente -já que cada uma delas precisa de um ataque específico- mas também os evidentes vínculos que existem entre elas.

Outro aspecto importante das propostas de Forrester -vinculado a críticas a suas previsões -está relacionado com a questão da "parametrização do modelo." Não é um problema grave, nem do ponto de vista técnico do processo de simulação nem do ponto de vista conceitual, mas a falta de seu esclarecimento cria uma área de vulnerabilidade na discussão global. Com efeito, Forrester fez predições ${ }^{43}$ indevida e injustificadamente precisas (que o tornam vulnerável a ataques interessados) sobre os limites do crescimento. Em suas afirmações (ou conclusões) ele privilegiou os 
limites "dos recursos naturais:" terra, combustíveis derivados do petróleo e do carvão mineral, etc. Podemos considerar que eles constituem "os inputs" do sistema produtivo. De alguma forma, nos primeiros tempos de aplicação dos modelos, atribuiuse uma atenção menor aos detritos e emissões industriais, talvez porque a quantificação de limites para esses parâmetros fosse uma tarefa de extrema dificuldade ou porque não haviam sido desenvolvidos os métodos que permitissem avaliar seus efeitos sobre o ecossistema, principalmente os de longo prazo. Eu colocaria estes fatores do lado do "output". O conjunto destes fatores, isto é, de todos os elementos nocivos produzidos pela atividade humana que se acumula no ecossistema, está atualmente sendo chamado de "ecological footprint."

A consideração em separado do lado "input" e do lado "output" é uma simplificação, e uma conveniência, não só de parametrização como também estratégica. Em princípio, soluções para estas categorias diferentes de problemas admitem tratamentos e tempos de resposta diferenciados. Hoje, muitos afirmam que a tecnologia, o desenvolvimento científico aplicado aos processos produtivos, principalmente na área agrícola, a substituição (atual e potencial) de combustíveis, etc. afastaram um pouco o fantasma desse lado do sistema produtivo. ${ }^{44}$ Infelizmente, esses fatos possibilitam os donos do planeta a ficarem menos preocupados e se sentirem autorizados a afirmar -como o fez The economist ${ }^{45}$ - que as previsões de Forrester estavam equivocadas. Mas, se pelo lado do input a situação talvez não tenha piorado com a velocidade anunciada por Forrester, pelo lado do output o deterioramento alcançou dimensões aterradoras, como nos exemplos mencionadas no início deste artigo. Mais ainda, se o lado do input aceita alguns placebos, não parece que isso possa acontecer do lado do output. Para piorar a situação, qualquer solução que seja tentada neste lado sofrerá uma indesejável demora para ser sentida, porque é justamente neste lado que os efeitos são cumulativos e de longo prazo.

O loop central do modelo encontra outras estruturas que reforçam sua tendência ao crescimento exponencial. Eles somam sua ação aos loops das FIGs. 2A e 2B e a outros loops que não consideramos neste trabalho. Pelas suas características, justifica-se considerar o loop mencionado a seguir (FIG. 11) também como de reforço, mas desta vez apoiado em propósitos nobres:

Sem que isto signifique renunciar ao questionamento do sistema capitalista ${ }^{46}$ e do efeito do comportamento dos consumidores, com o quê nem todos os interessados no ecossistema concordariam, podemos identificar a existência de uma tarefa comum: a de encontrar "pontos de alavancagem," isto é, medidas, políticas e ações que fiquem dentro do campo de nossas possibilidade e de nossos valores compartilhados que venham a contribuir com a preservação do ambiente. Nesta linha muito pode ser feito, principalmente em dois aspectos importantes: o aumento da ecoeficiência e a utilização de métodos de produção limpos. Randers ${ }^{47}$ faz o seguinte comentário a esse respeito:

"Increased eco-efficiency and clean production methods produce a reduction in the footprint per unit of consumption, but this is not fast 
enough to counter the growth in volume. Currently global production expands at around 3\% per year, while technology only reduces the specific footprint by around $2 \%$ per year. These are completely in the line with the "dynamic technology" loop of World3." (RANDERS, 2000)

A afirmação de Randers nos transmite dois recados. $\bigcirc$ primeiro -o recado ruim- é de que, se anualmente o ecossistema recebe 1\% em excesso do volume de contaminação produzido pelo sistema econômico que ele pode processar ou neutralizar (i. é., que se acumula), isso significa que, ao longo do tempo, a quantidade de poluentes acumulados crescerá exponencialmente. Mas o processo é ainda mais perverso, uma vez que, devido a não linearidade, os efeitos negativos tendem a ser muito piores do que já são (e.g., se uma determinada quantidade de poluentes mata árvores a uma certa taxa, mesmo sob a hipótese de que se mantenha a mesma quantidade de poluentes, o efeito tende a ser mais grave devido ao fato de que teremos cada vez menos árvores para absorve-lo, produzindo assim um duplo ciclo de feedback positivo de efeitos perversos).

A boa notícia é que a eco- eficiência é uma variável cujo valor pode ser aumentado por fatores que estão sob nosso controle: conhecimento, compromisso e organização social. Aqui também o Raciocínio Sistêmico pode ser de grande ajuda, principalmente na formulação e desmembramento estratégico. Essa ajuda é oferecida por duas outras vertentes do Raciocínio Sistêmico: a linha da Quinta Disciplina, liderada por Peter Senge ${ }^{48}$-derivada e com forte interseção com a linha de Forrester- e a linha da Action Research, de Kurt Lewin ${ }^{49}$, cujas fontes se localizam nas ciências sociais.

Se a linha de Forrester - na forma em que aqui foi apresentada-é essencial para a gestão global, a de Senge o é para a gestão local. Esta escola coloca para isso, à disposição do praticante, uma vasta gama de métodos e ferramentas que permitem lidar com questões tais como: planejamento participativo, aprendizado em equipe, criação de visão de futuro, planejamento por cenários, planejamento estratégico do ponto de vista sistêmico, definição e avaliação de políticas e diretrizes, envolvimento pessoal, organizações de aprendizado, etc. Ao longo dos últimos dez anos tivemos oportunidade de aplicar estas metodologias - muitas vezes após um processo de modificação e adaptação a cada caso e circunstância- no planejamento de um Estado brasileiro, de numerosos municípios e de organizações comunitárias. Em todos os casos em que foi aplicada, devido ao poder das metodologias, o sucesso foi além do esperado.

\section{CONCLUSÓES FINAIS}

Ao redigir este texto, meu propósito foi o de apresentar os prolegômenos do Raciocínio Sistêmico com a profundidade mínima necessária para introduzir o tema como ponto de discussão. Além disso, como não deixo de sentir alguma perplexidade ao constatar as poucas menções que se fazem às metodologias contidas no Raciocínio Sistêmico na literatura dedicada aos ecossistemas, um de meus propósitos foi o de convencer um maior número de especialistas da área a familiarizar-se com este recurso. Como crente convicto, talvez eu não seja muito objetivo ao avaliar seu potencial de 
aplicação, mas ainda espero que apareça alguém que prove o contrário.

Tentei ser breve para que o material ocupe o mínimo possível de páginas da revista. Tentei que o artigo fosse auto-sustentado e sem parafernálias técnicas, para que todos os leitores pudessem entender os conceitos. Minha meta era de que adolescentes, tais como Felipe (12) e Marina (17), pudessem ler sem dificuldade e entender o material apresentado. Tentei ser sedutor em meus argumentos, para induzir o maior número de leitores à prática sistêmica. Tentei ser provocativo, para estimular críticas e discussões, única forma de garantir o avanço da disciplina. Tentei ser rigoroso nos conceitos, para não enfraquecer a imagem da disciplina aos olhos dos críticos furtivos. Tentei mostrar que o Raciocínio Sistêmico constitui um campo aberto ao interesse de alunos e pesquisadores que poderiam realizar trabalhos nesta área. Se não consegui nada disso é por minha própria incompetência, e não por alguma característica negativa da disciplina. Entretanto, se existe algum mérito, dedico o esforço realizado a Chico Mendes, que aprendeu a metodologia do Raciocínio Sistêmico andando pela floresta (e que foi assassinado por praticá-lo).

\section{BIBLIOGRAFIA}

BERTALANFFY, L. V. General System Theory: essential concepts and applications. Tunbridge Wells, 1969.

CARONE, M. Mais, Folha de São Paulo; 14/10/97.

CHECKLAND, P. Systems Thinking, Systems Practice. Chichester, John Wiley, 1981. DE GEUS, A. "Planning as Learning" Harvard Business Review, March-April, 1988.

DESCARTES, R. Discourse on Method, London, J.M. Dent, 1962.

DOYLE, J. \& FORD, D. "Mental Models Concepts for Systems Dynamics Research", System Dynamics Review, Vol. 14, 1998.

FERREIRA, L. C. "Sustentabilidade e democracia no poder local" Ambiente $\mathbb{E}$ Sociedade, Ano 1, N0 1, segundo semestre de 1997.

FORRESTER, J. W.. "Learning through System Dynamics as Preparation for de $21^{\text {st }}$ Century". Collected Papers of J. W. Forrester. Portland, OR. Productivity Press., 1975.

FORRESTER, J. W. World Dynamics. Pegasus Communication, 1971.

FORRESTER, J. W. Industrial Dynamics; Productivity Press, 1961.

FORRESTER, J. W. Urban Dynamics, Mass., Cambridge, MIT Press, 1969.

GOODMAN, M. \& KARASH, R. "Six steps to Thinking Systematically", The Systems Tinker, Vol 6, No. 2, 1965.

LAHOZ, A. "Porque os economistas erram", Revista Exame, ano 31, No 8, 1998, pp. 104.

LEONTIEF, W. “Academis Economics”, Science, 217; 1936, pp. 104-107.

LEWIN, K. "Frontiers in Group Dynamics; Social Planning and Action Research." Human Relations, 1, 143-153, 1947.

LUX, K. O erro de Adam Smith, São Paulo, Editora Nobel.

MACK, R. et al. "Biotic invation: causes, epidemiology, global consequences, and 
control." Ecological Applications, 10(3), pp. 689-710, 2000.

MARX, K. O Capital, São Paulo, DIFEL: Difusão Editorial, 1984.

MEADOWS, D. H.; MEADOWS, D. L., RANDERS, J. Beyond the Limits. Chelsey

Green: Posst Mills, 1992.

MEADOWS, D. H.; MEADOWS, D. L.; RANDERS, J.; BEHEREN, W. The limits to Growth. Universe Press, 1972.

MORECROFT, J. \& STERMAN, J. Modeling for Learning Organizations. System Dynamics Series. Productivity Press, 1994.

NORGAARD, R. B. "A improvisação do conhecimento discordante", Ambiente $\mathcal{E}$ Sociedade, Ano 1, No. 2, primeiro semestre de 1998.

ODUM, H. T. Ecological and General Systems Practice. Chichester, John Wiley, 1994.

RANDERS, J. International System Dynamics Society Conference, Bergen, Norway, Aug. 2000.

RICHARDSON, G. P. Feedback Thought in the Social Sciences and Systems Theory. Pegasus Communications, 1999.

RICHMOND, B. "Systems Thinking: critical skills for the 1990s and beyond", System Dynamics Review, Vol9, No. 2, 1993. pp. 113-133.

SAEED, K. Development Planning and Policy Design, Alderschot, Averbury Books, 1994.

SENGE, P. The Fifth Discipline: The Art and Practice of the Learning Organization; London, Century, 1990.

SENGE, P. The Fifth Discpline: Fieldbook, London, Century, 1994.

STINCHOME, A. L. Constructing Social Theories . New York: Harcourt, Brace and World, 1968.

\section{NOTAS}

* Ph. D. em Estatística, Universidade da California, Berkeley; Prof. (aposentado) do Departamento de Estatística da UNICAMP, ex-coordenador do Mestrado em Qualidade da UNICAMP, e consultor na Área de Planejamento Estratégico.

${ }^{1}$ De fato, o problema ambiental é cada vez mais introjetado como tema na gestão empresarial por dois motivos principais: primeiro, porque a legislação ambiental orientada ao sistema produtivo está se tornando cada vez mais rigorosa, atingindo o caixa das empresas descuidadas; em segundo lugar, porque para os empresários mais espertos, o problema ambiental se constituiu em uma oportunidade de negócios.

${ }^{2}$ NORGAARD, 1998.

${ }^{3}$ Tal vez, mais do que uma linguagem comum, ele poderia tornar-se um código de comunicação universal dentro da área.

${ }^{4}$ FERREIRA, 1997.

${ }^{5}$ Modesto Carone: Folha de S.P. - Mais 14-10-97. Pg. 3-5. “...a rigor, so é kafkiana a situação do indivíduo moderno, tal como o conhecemos às voltas com a trama de poder que toma conta de sua vida, sem que ele ache uma saída para esse tipo por assim dizer planetário de alienação. Na verdade é ela que decreta a impossibilidade do personagem construir um destino próprio, o que transforma todos seus esforços em um padrão de iniciativas inúteis." 
"È natural que uma circunstância assim esclareça por que, neste universo que segue o curso de uma história cega, (é o obstáculo que vence, e não o contrário), seja obrigado a fazer um caminho cuja orientação profunda ele desconhece, sabendo porém que ela existe... ele não é capaz de nomeá-la devido á distância entre os superpoderes que o submete e o seu ponto de vista particular, que é sempre parcelado.

Essa visão (ou falta de visão) do todo não é apenas um assunto, ela está introjetada.”

${ }^{6}$ FORRESTER; 1973.

${ }^{7}$ MACK et al., 2000, pp 689-710.

${ }^{8}$ Não acreditamos que aqueles que utilizam variedades africanas de grama como alimento de gado na Amazônia tenham a "intenção" de produzir desertificação. Sua intenção é apenas maximizar o lucro, a desertificação a conseqüência não intencional.

${ }^{9}$ L. BERTALANFFY, 1969:

${ }^{10}$ A. RAPOPORT, 1986.

${ }^{11}$ J.W. FORRESTER, 1971.

12 P. SENGE, 1990.

${ }^{13}$ P. SENGE, 1994.

${ }^{14}$ H.T. ODUM, 1994.

${ }^{15}$ Incluímos estes conceitos para tornar o artigo conceitualmente auto-sustentado. O material pode ser encontrado em qualquer livro sobre dinâmica de sistemas.

${ }^{16}$ Um exemplo interessante de loop de feedback (ou relação de causalidade circular) é descrito por MARX (1984). Ele afirma: “... a mais valia se origina do capital e... o capital nasce da mais valia.”(pg. 674).

${ }^{17}$ Talvez não com a velocidade e intensidade suficientes, diversas formas de legislação ambiental estão sendo progressivamente aplicadas. No número 3, pag. 151 da publicação The McKinsey Quarterly, MERK \& ROBINSON reportam que os gastos por responsabilidade legal, por riscos ambientais, das corporações americanas supera os 250 bilhões de dólares anuais. Eles afirmam, também, que o montante é muito maior, mas que aparece dissimulado em obscuros sistemas contábeis. Um outro exemplo de aumento da preocupação é o crescente uso das normas ambientais (ISO).

${ }^{18}$ RICHARDSON, 1999.

${ }^{19}$ MARUYAMA, 1963.

${ }^{20}$ FORRESTER, 1969.

${ }^{21}$ Os habitantes de muitas cidades brasileiras, principalmente São Paulo, têm sido vítimas deste tipo de propostas. A diferença está no fato de que eles nunca tiveram chance de se manifestar - nem foram educados para isso. Talvez, se no futuro eles forem conscientizados de que essas propostas envolvem falsas soluções, eles exijam ser ouvidos.

${ }^{22}$ Os historiadores da ciência afirmam que as acusações mais importantes que os inquisidores levantaram contra ele foi em relação a esse fato e não ao de que a terra se movia. Durante séculos a acusação foi mantida. Só neste século ele foi "perdoado" pelo Vaticano.

${ }^{23}$ Entretanto, não podemos esquecer a observação de Schumpeter: "Não existe nada mais prático que uma boa teoria."

${ }^{24}$ Não podemos deixar de observar um vínculo entre esses dois fenômenos.

${ }^{25} \mathrm{O}$ uso de fluxos e acumuladores (stocks and flows) permite uma representação diagramática dos sistemas mais completa que a forma por nós utilizada neste texto. Ela é também mais adequada para se construir modelos de simulação. Entretanto, ela é bastante mais complexa, na nossa opinião é também menos intuitiva e, consequentemente, menos apropriada para trabalho com grupos de pessoas não especialistas.

${ }^{26}$ Talvez esta seja a perspectiva dominante sobre Raciocínio SistêmicoS. Ela não é incorreta, mas é incompleta.

${ }^{27}$ Neste parágrafo, mencionamos essencialmente as idéias apresentadas em "Systems thinking: critical skills for 
the 1990s and beyond”, in BARRY RICHMOND, 1993.

${ }^{28}$ Para um relato interessantíssimo sobre as Cooperativas Industriais de Mondragon, ver LUX, O erro de Adam Smith, Editora Nobel, Capítulo 10.

${ }^{29} \mathrm{Na}$ área comercial, os modelos de predição representam um mercado bilhionário. LAHOZ, (1998) arrisca a cifra de 200 bilhões de dólares por ano, só nos EUA. O autor desse artigo menciona também o fato de que a maioria das predições constitui um triste fracasso.

30 "Correlacional" porque se apoia no grau de correlação estatística entre o output do modelo e as observações do sistema real. O critério afirma, em princípio, que uma correlação alta indica que o modelo é válido.

${ }^{31}$ Método e/ou critério para avaliar o ajuste de curvas a números ou observações

${ }^{32}$ MORECROFT \& STERMAN, 1994.

${ }^{33}$ Na nossa opinião, a educação ambiental é uma das resposabilidades mais esquecidas da comunidade científica preocupada com o meio ambiente. Essa tarefa, ou melhor, a simples disseminação, é deixada para jornalistas, muitas vezes bem intencionados, nem sempre bem preparados e, geralmente, com uma visão parcial, sensacionalista ou romântica do problema, o que poucas vezes produz mudanças de alto impacto nos comportamentos dos diversos grupos sociais envolvidos.

${ }^{34}$ MATIAS, 1994.

${ }^{35}$ O livro de RICHARDSON (1999), embora com um estilo pouco claro, representa uma rica e interessante fonte de exemplos de pensamento sistêmico em ciências sociais ao longo do tempo

${ }^{36}$ FORRESTER, 1971.

${ }^{37}$ D.H.MEADOWS, D.L. MEADOWS, J. RANDERS, W. BEHEREN, 1972.

${ }^{38}$ D.H.MEADOWS, D.L. MEADOWS, J. RANDERS, 1992.

${ }^{39}$ Mais tarde, em 1986 a Comissão Brundland (UN Comission on Enviromental Development 1987) propõe sem mudar o conceito- a expressão "desenvolvimento sustentável" em substituição ao termo "equilíbro" de Forrester. A partir desse momento, o conceito foi exprimido em termos de suas componentes: sustentabilidade financeira, sustentabilidade ambiental e, mais recentemente, sustentabilidade social. Uma discussão completa destas componentes, e de suas interações, estaria plenamente justificada pela sua importância, porém nos levaria além dos limites razoáveis deste trabalho. O fato de ter dado origem ao conceito de desenvolvimento sustentável é suficiente para valorizar o impacto que o raciocínio sistêmico teve na análise dos problemas globais. Para uma consideração mais profunda sobre estes temas, ver SAEED, (1994).

${ }^{40}$ Em todo nosso discurso fica desde já implícito que atribuímos à atividade econômica (que gera o output) a responsabilidade de "consumir" recursos naturais e de produzir detritos de todo tipo, culpados pela contaminação ambiental.

${ }^{41}$ Poder-se-ia dizer que, no caso de países,é também o poder, que para se manter precisa se alimentar de mais poder, sempre apoiado na maquina militarista e de domínio econômico.

${ }^{42}$ Isso não acontece por acaso: o status é a mercadoria que mais se vende. Além demais, ela tem a característica de que qualquer que seja o volume produzido, sempre fica aquém da demanda.

${ }^{43}$ Infelizmente ele também caiu nessa tentação.

${ }^{44}$ Em ocasiões a solução de um problema do lado do input transferiu o o problema para o lado do output. Como exemplo podemos mencionar o caso dos combustíveis nucleares, que poderiam ser uma excelentes solução como substituição de combustíveis de origem mineral mas que geram lixo atómico, além dos problemas de riscos operacionais.

${ }^{45}$ The Economist. 1997. Plenty of gloom. December 20, p. 21. Mencionado por RANDERS, 2000.

${ }^{46}$ Talvés a União Soviética cometeu os maiores crimes contra o ecossistema ao explorar de maneira criminosa sua florestas gelados para vender sua madeira.

${ }^{47}$ RANDERS, 2000.

${ }^{48}$ SENGE, 1990.

${ }^{49}$ LEWIN, 1947. 


\section{Manuel Folledo}

\section{Raciocínio Sistêmico - uma boa forma de se pensar o meio ambiente}

Os sistemas ecológicos são muito mais complexos e difíceis de entender que os sistemas tecnológicos. Consequentemente, se nós estivermos interessados em produzir uma reestruturação radical nestes sistemas, necessária para resolver os problemas mais dramáticos do mundo atual, deveremos fazê-lo de forma diferente para que possamos alcançar um melhor entendimento desses problemas. Este artigo mostra como a metodologia do Raciocínio Sistêmico pode ser utilizada como uma componente fundamental para atingir esse entendimento e mostra as características essenciais que fazem deste enfoque algo diferente de todos os outros métodos. Com este propósito, o artigo oferece um conjunto básico de métodos e idéias visando ao entendimento do ambiente desde um ponto de vista sistêmico.

Palavras-chave: Sistemas, Eco-sistemas, Raciocínio Sistêmico, Modelos Mentais, Estruturas Sistêmicas, Modelos de Simulação

\section{System Thinking: a proper approach to understand the environment}

Ecological systems are far more complex and harder to understand than tecnological systems. If we want a radical system restructure, necessary to solve the world's most dramatic problems, we must think differently in order to obtain a better understanding of these issues. This paper will address how the System Thinking method can be used as a major tool to achieve this goal. It highlights the difference of this approach providing some basic ideas and methods to understand the enviroment from a systemic point of view.

Keywords: Systems, Ecosystems, Systemic Thinking, Mind Models, Systemic Structures, Simulation Models. 